AlQ $1:$ किष

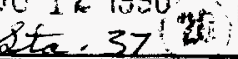

ENGINEERING DATA TRANSMITTAL

Page 1 of

2. To: (Receiving Organization)

Distribution

3. From: (Originating Organization)

GF Vargo, Jr. $/ 75250$

5. Proj./Prog./Dept./Div.:

6. Cog. Engr.:

CA Esvelt

1. EDT 607011

Characterization Equipment

Devel opment

8. Originator Remarks:

For Review and Approval

For Review and Approval

11. Receiver Remarks:

4. Related EDT No.:

$N / A$

7. Purchase order No.:

$N / A$

9. Equip./Component No.:

$N / A$

10. System/Bldg./Facility:

$N / A$

12. Major Assm. Dwg. No.:

$N / A$

13. Permit/Permit Application No.: $N / A$

14. Required Response Date:

\title{
$8|1| 96$
}

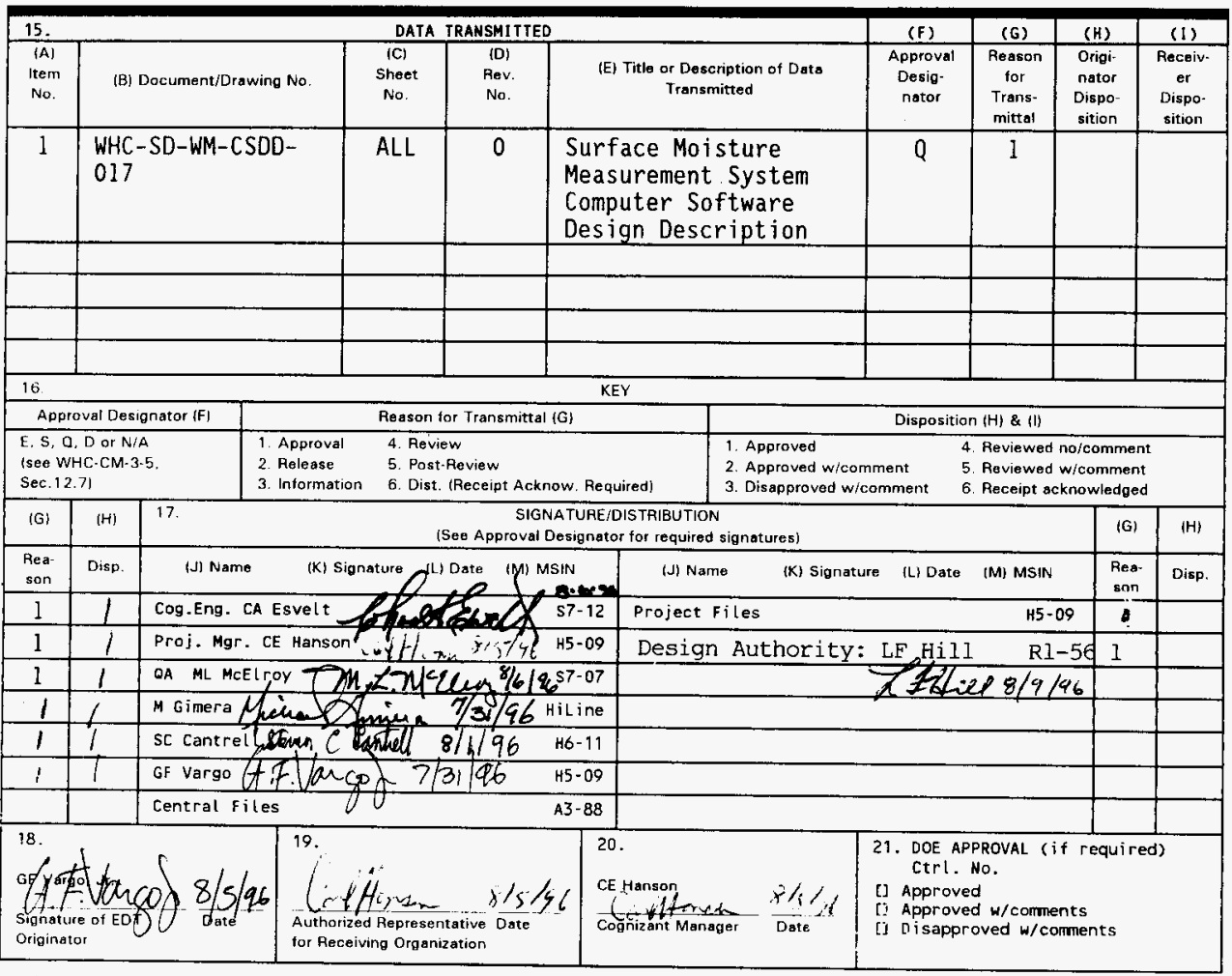

BD-7400-172-2 (04/94) GEF097 


\title{
SURFACE MOISTURE MEASUREMENT SYSTEM COMPUTER SOFTWARE DESIGN DESCRIPTION
}

\author{
George F. Vargo Jr. \\ Westinghouse Hanford Company, Richland, WA 99352 \\ U.S. Department of Energy Contract DE-AC06-87RL10930 \\ EDT/ECN: 607011 UC: 2070 \\ Org Code: 75250 Charge Code: N4H4F \\ B\&R Code: EW3120074 Total Pages: 81
}

Key Words: Surface Moisture Measurement System, Computer Software Design Description, CSDD, Liquid Observation Well Moisture Measurement System

Abstract: This document describes the software that performs the data acquisition for the SMMS instrument. This document was created with graphical programming language. The software described in this document was written to comply with the Software Requirements Specification. Hardware is described in Section 2. Software is described in Section 3.

\footnotetext{
TRADEMARK DISCLAIMER. Reference herein to any specific comercial product, process, or service by trade name, trademark, manufacturer, or otherwise, does not necessarily constitute or imply its endorsement, recommendation, or favoring by the United States Government or any agency thereof or its contractors or subcontractors.

Printed in the United States of America. To obtain copies of this document, contact: WHC/BCS Document Control Services, P.0. Box 1970, Mailstop H6-08, Richland WA 99352, Phone (509) 372-2420; Fax (509) 376-4989.
}
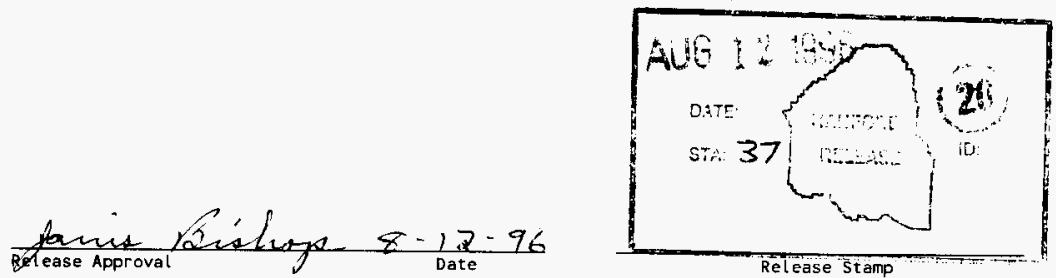

\section{Approved for Public Release}




\title{
SURFACE MOISTURE MEASUREMENT SYSTEM COMPUTER SOFTWARE DESIGN DESCRIPTION
}

APPROVAL LEVEL Q

\author{
Issued by \\ Michael Gimera \\ July 1996
}

HiLine Engineering \& Fabrication Inc. 


\section{TABLE OF CONTENTS}

SECTION

PAGE

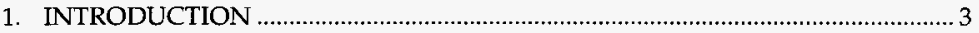

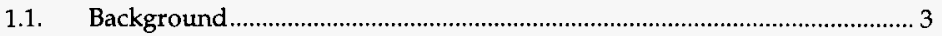

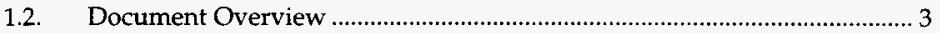

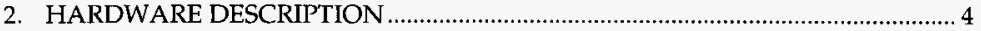

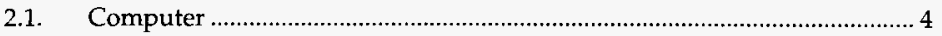

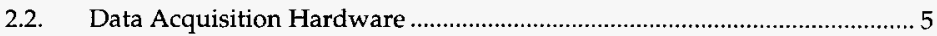

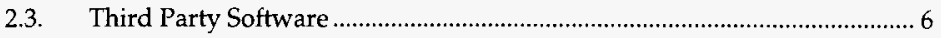

3. Surface Moisture Measurement System SOFTWARE …........................................ 6

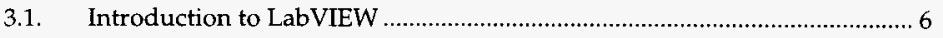

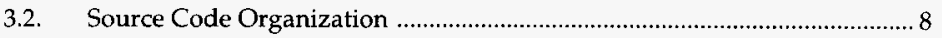

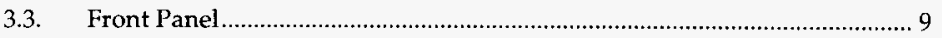

3.4. Main Program (Block Diagram) ................................................................. 10

3.4.1. Update Temperature Event ................................................. 11

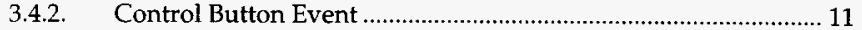

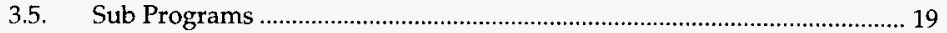

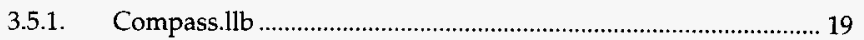

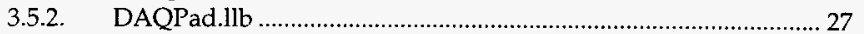

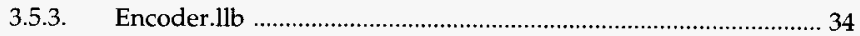

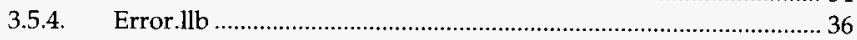

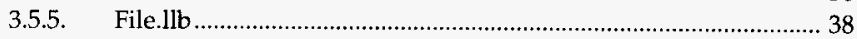

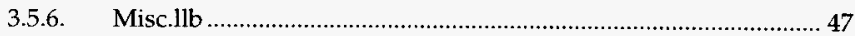

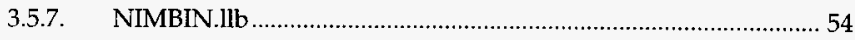

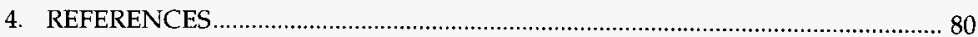




\section{SURFACE MOISTURE MEASUREMENT SYSTEM COMPUTER SOFTWARE DESIGN DESCRIPTION}

\section{INTRODUCTION}

\subsection{BACKGROUND}

Radioactive wastes from defense operations have accumulated in underground waste storage tanks at the Hanford Site since the 1940's. Potential fuels, in the form of ferrocyanide and various organic compounds, may be present in many of these tanks. Safety concerns have risen based on the possibility of condensed phase chemical reactions propagating into undesirable consequences.

Analyses and experiments indicate that the reaction propagation and possibility its initiation may be precluded by the presence of sufficient concentration of moisture in the waste. If sufficient moisture is present in a fuel-containing waste boundary between an initiated reaction and a dry stoichiometric mixture of fuel and oxidizer, modeling predicts that the water will absorb the energy released from the reaction so that it will not propagate through the waste boundary. Because the credible reaction initiators would be expected to occur at the waste surface, sufficient moisture concentration in the top layers of waste would, under current safety guidelines, provide evidence that the tank waste is in a stable and safe form for continued storage.

The Surface Moisture Measurement System (SMMS) was developed by Westinghouse Hanford Company (WHC), Science Applications International Corporation (SAIC), and HiLine Engineering \& Fabrication Inc. (HiLine) to determine the moisture concentration in the upper layers of the waste surface. Waste moisture concentration profiles for tanks that contain liquid observation wells (LOW) will be obtained with the Liquid Observation Well Moisture Measurement System (LOWMMS), which is controlled using the same data acquisition and control system as the SMMS. The LOWMMS will provide a second method of measuring the waste immediately surrounding the LOW and will help confirm the measured surface moisture obtained with the SMMS.

\subsection{DOCUMENT OVERVIEW}

This document describes the software that performs the data acquisition for the SMMS instrument. The format of the document may differ from typical Software Design Reports because it was created with a graphical programming language.

The software described in this document was written to comply with the Software Requirements Specification (SRS), WHC-SD-WM-SFR-010.

Hardware is described in Section 2. The purpose of this document is to describe the software, so the hardware description is brief. 
Software is described in Section 3. LabVIEW ${ }^{(1)}$ was used to develop the SMMS software, so Section 3 begins with an introduction to LabVIEW ${ }^{\circledR}$. This is followed by a description of the main program. Finally each HiLine developed subVI (sub program) is discussed.

\section{HARDWARE DESCRIPTION}

The SMMS is comprised of the following components:

- A neutron probe. The probe contains a neutron source, three detectors and two thermisters.

- A deployment device. The deployment device consists of an enclosure, a mast and forearm. On the enclosure is mounted a compass and encoder to measure the direction the forearm is pointed and the distance the probe is lowered below the forearm. The forearm can be raised and lowered on the mast which moves the probe in relation to the riser centerline and the distance is measured with an inclinometer located in the forearm. The enclosure also contains three digital readout for compass direction, vertical distance and distance from riser centerline.

- A data acquisition van which houses a NIMBIN for processing counts from the neutron detectors and the data acquisition computer.

- A decontamination system that operates independently from the SMMS software.

\subsection{COMPUTER}

Data acquisition for SMMS is accomplished with an industrial computer housed in the data acquisition van. The operator interface with the system is through point-and-click on the computer's flat panel touch screen using the system mouse or touch screen for input. Each front panel control accessible to the operator is represented by an icon on the computer monitor display. These icons can be accessed and manipulated with the computer's mouse pointer.

Using the computer monitor screen, mouse, and keyboard, the operator can select the operating parameters.

The data acquisition and control computer is an IBM ${ }^{\mathbb{B} 2}$ compatible system. It includes the following features:

- $90 \mathrm{MHz}$ Pentium ${ }^{\circledR 3}$ CPU

${ }^{1}$ LabVIEW is a registered trademark of National Instruments, Corp., Austin, TX.

${ }^{2}$ IBM is a registered trademark of the Internationa Business Machines, Corp., Boca Raton, FL.

${ }^{3}$ Pentium is a registered trademark of Intel, Sunnyvale, CA. 
- 40 MBytes Random Access Memory

- One GByte Hard Disk Drive

- 3.5 inch, 1.4 MByte Floppy Disk Drive

- Three ISA (Industry Standard Architecture) bus slots

- Three PCI (Peripheral Component Interconnect) bus slots

- One ISA/PCI slot

- Two Serial Ports and One Paraliel Port

- Microsoft Compatible Mouse

- A flat panel active matrix touch screen

The computer is mounted inside an industrial enclosure in the data acquisition van.

\subsection{DATA ACQUISITION HARDWARE}

The following hardware is connected to the computer for data acquisition:

National Instruments ${ }^{\circledR 4}$, AT-DIO-32F, located in ISA bus slot 1 . This board interfaces to the encoder and acquires 32 bits of digital data. The base address is 240 hex and uses IRQ 5. Uses Read From Digital Port.vi.

National Instruments ${ }^{\circledR 5}$, AT-AO-6, located in ISA bus slot 2.. This board interfaces to the digital readout indicators on the deployment device. It outputs 3 channels of analog data. The base address is $1 \mathrm{CO}$ hex and uses IRQs 10,12. Uses AO Update Channel.vi.

National Instruments ${ }^{(16}$, DAQPad-1200, connected to the parallel port. This device interfaces to the thermisters and inclinometer. The base address is 378 hex and uses IRQ 7. Uses AI Sample Channels.vi.

The electronic compass is connected to COM port 1 . It communicates at 9,600 baud, 8 data bit, no parity and one stop bit. Uses Serial Port Write.vi, Serial Port Read.vi and Byte at Serial Port.vi.

A SCSI (Small Computer Serial Interface) card is installed one of the PCI slots. The data archiving drive is connected as SCSI ID 7 using IRQ 11. Uses the LabVIEW ${ }^{\circledR}$ copy command.

\footnotetext{
${ }^{4}$ National Instruments is a registered trademark of National Instruments Corp., Austin, TX.

${ }^{5}$ National Instruments is a registered trademark of National Instruments Corp., Austin, TX.

${ }^{6}$ National Instruments is a registered trademark of National Instruments Corp., Austin, TX.
} 


\subsection{THIRD PARTY SOFTWARE}

Software is required to support Westinghouse Hanford developed SMMS software. This other software consists of MS-DOS ${ }^{\circledR 7}$ version 6.2 and Windows ${ }^{\circledR 8}$ version 3.1 from Microsoft. No additional software is required to operate the SMMS software.

For development purposes, additional software is required to compile to SMMS source code. This software is: LabVIEW for Windows Picture Control Kit ${ }^{\circledR 9}$ (Version 3.0.1) from National Instruments ${ }^{\circledR 10}$ and Peek/Poke $2.0^{\circledast 11}$ from Viewpoint Software Solutions, Inc ${ }^{\circledR 12}$.

Development was done with LabVIEW ${ }^{\circledR}$ for Windows full development system version 3.0.1 from National Instruments ${ }^{(\mathbb{1}}$.

\section{SURFACE MOISTURE MEASUREMENT SYSTEM SOFTWARE}

This section provides the descriptions of the SMMS software. When listing LabVIEW ${ }^{(1)}$ source code empty frames are omitted. An example of this is conditional statement that is only executed if a statement is true, but no action is taken upon a false condition.

\subsection{INTRODUCTION TO LABVIEW}

LabVIEW $^{\circledR}$ is a program development application, much like C, Pascal or FORTRAN. However, LabVIEW ${ }^{\circledR}$ is different from those applications in one important respect. Other programming systems use text-based languages to create lines of code, while LabVIEW ${ }^{\circledR}$ uses a graphical programming language, $G$, to create programs in block diagram form.

LabVIEW $^{\circledR}$ is a general-purpose programming system, but it also includes libraries of functions and development tools designed specifically for data acquisition and instrument control. LabVIEW ${ }^{\circledR}$ programs are called virtual instruments (VIs) because their appearance and operation imitate actual instruments. However, they are identical to functions from conventional programs. VIs have an interactive user interface, a

${ }^{7}$ MS_DOS is a registered trademark of Microsoft Corp., Redmond, WA.

${ }^{8}$ Windows is a registered trademark of Microsoft Corp., Redmond, WA.

${ }^{9}$ LabVIEW for Windows Picture Control Kit is a registered trademark of National Instruments Corp., Austin, TX.

10 National Instruments is a registered trademark of National Instruments Corp., Austin, TX.

${ }^{11}$ Peek/Poke is a registered trademark of Viewpoint Software Solutions, Inc.

${ }^{12}$ Viewpoint Software Solutions is a registered trademark of Viewpoint Software Solutions, Inc. 
source code equivalent, and accept parameters from higher level VIs. These three VI features are discussed below.

- The interactive user interface of a VI is called the front panel, because it simulates the panel of a physical instrument. The front panel can contain knobs, push buttons, graphs, and other controls and indicators. You input data using a mouse and keyboard, and then view the results on the computer screen.

- The VI receives instructions from a block diagram, which you construct in G. The block diagram is a pictorial solution to a programming problem. The block diagram is also the source code for the VI.

- VIs are hierarchical and modular. You can use them as top-level programs, or as subprograms within other programs or subprograms. A VI within another VI is called a subVI. The icon and connector of a VI work like a graphical parameter list so that other VIs can pass data to a subVI.

With these features, LabVIEW ${ }^{\circledR}$ promotes and adheres to the concept of modular programming. An application can be divided into a series of tasks, which can again be divided until a complicated application becomes a series of simple subtasks.

The block diagram is the graphical source code of a LabVIEW ${ }^{(B)}$ VI. A block diagram is constructed by wiring together objects that send or receive data, perform specific functions, and control the flow of execution.

Nodes are program execution elements. They are analogous to statements, operators, functions, and subroutines in conventional programming languages. The Add or Subtract functions are one type of node. LabVIEW ${ }^{(B)}$ has an extensive library of functions for math, comparison, conversion, $\mathrm{I} / \mathrm{O}$, and more. Another type of node is a structure. Structures, similar to loops and case statements in traditional programming languages, repeatedly or conditionally execute code. LabVIEW ${ }^{\circledR}$ also has special nodes for linking to external text-based code and for evaluating text-based formulas.

Wires are data paths between source and sink terminals. A source terminal cannot be wired to another source terminal or wire a sink terminal to another sink, but a source can be wired to several sinks. Each wired has a different style or color depending on the data type that flows through the wire.

The principle that governs LabVIEW ${ }^{\circledR}$ program execution is called data flow. Stated simply, a node executes only when data arrives at all its input terminals; the node supplies data to all of its output terminals when it finishes executing; and the data passes immediately from source to sink (or destination) terminals. Data flow contrasts with the control flow method of executing a conventional program, in which instructions are executed in the sequence in which they are written. Control flow execution is instruction driven. Data flow execution is data driven or data dependent.

When a VI operates as a subVI (the LabVIEW ${ }^{(B)}$ analog of a subroutine) inside another VI, the controls and indicators receive data from and return data to the calling VI. 
The icon represents a VI in the block diagram of another VI. The connector is a set of terminals that correspond to the subVI controls and indicators. The icon can be the pictorial representation of the purpose of the VI, or it can be a textual description of the VI or its terminals.

The connector is much like a parameter list of function call; the connector terminals act like parameters. Each terminal corresponds to a particular control or indicator on the front panel. A connector receives data at its input terminals and passes data to the subVI code via the subVI controls, or receives the results at its output terminals from the subVI indicators.

\subsection{SOURCE CODE ORGANIZATION}

The SMMS software source code is comprised of a main program, SMMS.VI and subprograms (subVI's) that are located in libraries. The following libraries contain VI's that are called by the main program:

Compass - Contains all VI's that are used to interface with the compass that is located on the deployment device.

Checksum.vi

Parse String.vi

Read Compass.vi

Send Compass Command.vi

XOR Bytes.vi

DAQPad - Contains all VI's that are provide analog input/output and solid state relay interface.

Convert to Radial Distance.vi

Convert to Volts.vi

Read DAQPad.vi

Temperature Stabilized.vi

Update Newport meters.vi

Encoder - Contains all VI's that are used to interface with the encoder that is located on the deployment device.

Calculate Position.vi

Read Encoder.vi

Error - Contains all VI's that are used to handle errors.

Error Handler.vi

Write to Error Log.vi

File - Contains all VI's that are used to read and write files.

Archive Files.vi

Create File.vi 


\author{
Date String.vi \\ Get Path.vi \\ Path/Date String.vi \\ Write Characters to File.vi \\ Misc - Contains miscellaneous VI's, such as global variables. \\ Options Screen.vi \\ SMMS Globals.vi \\ NIMBIN - Contains all VI's that are used to interface with the NIMBIN that is \\ located in the data acquisition van. \\ Check Progress.vi \\ Convert to Value.vi \\ Get Number of Ticks.vi \\ Get Response.vi \\ Get Spectrum.vi \\ Progress Bar.vi \\ Send Command.vi \\ Start Counting.vi
}

\title{
3.3. FRONT PANEL
}

The user interfaces with the software through the front panel (Figure 1). The front panel allows the user to begin taking measurement data or to move to a screen to set options associated with the data acquisition.

Visual feedback on position and data collection is provided to the operator. A polar graph displays probe position in turns of compass degrees and distance from the riser centerline in feet. Probe position is also displayed numerical below the polar graph. In addition to compass position and radial distance from riser centerline, the vertical distance (depth) is displayed in inches below the probe "home" position.

On the right side of the user interface screen spectrum data is displayed from each of the three detectors that are located in the probe. All three are displayed on the same axis and are distinguished by color. Above the spectrum graphs are the resulting counts per minute digital displays for each of the three detectors. Both the spectrum data and the counts per minute readouts are updated only after a measurement finishes.

On the bottom right of the user interface screen, located between the "take Measurement" control and the "Options" control is a digital display of temperature in the probe and an indicator light that is green if temperature has stabilized for five minutes and red if it has not.

On the bottom left of the screen is a control that allows the user to define the next measurement to be taken as a real test in the tank or an operation check of the probe. Operational checks are performed before entering the tank to verify correct operation of the probe. The only affect the setting of this control has is to write a statement to the resulting disk file indicating what type of data is being recorded. 


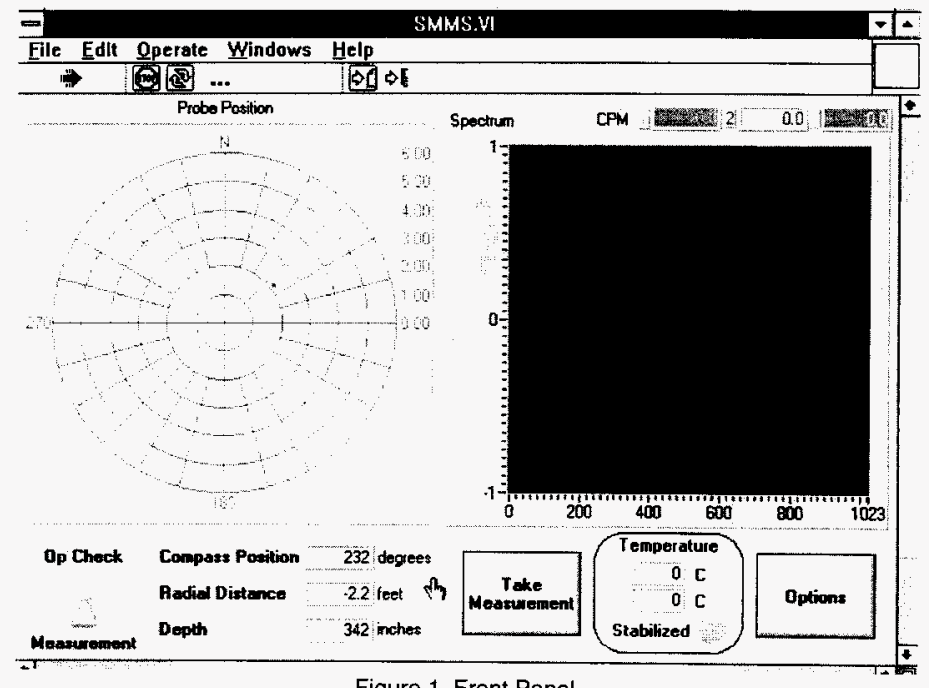

Figure 1 Front Panel

\subsection{MAIN PROGRAM (BLOCK DIAGRAM)}

The SMMS software consists of an infinite loop (Figure 2). This loop will continue to execute until the LabVIEW ${ }^{\circledR}$ stop icon is invoked. Inside the loop three distinct events happen, Update Temperature Event, Options Event and Take Measurement Event. 


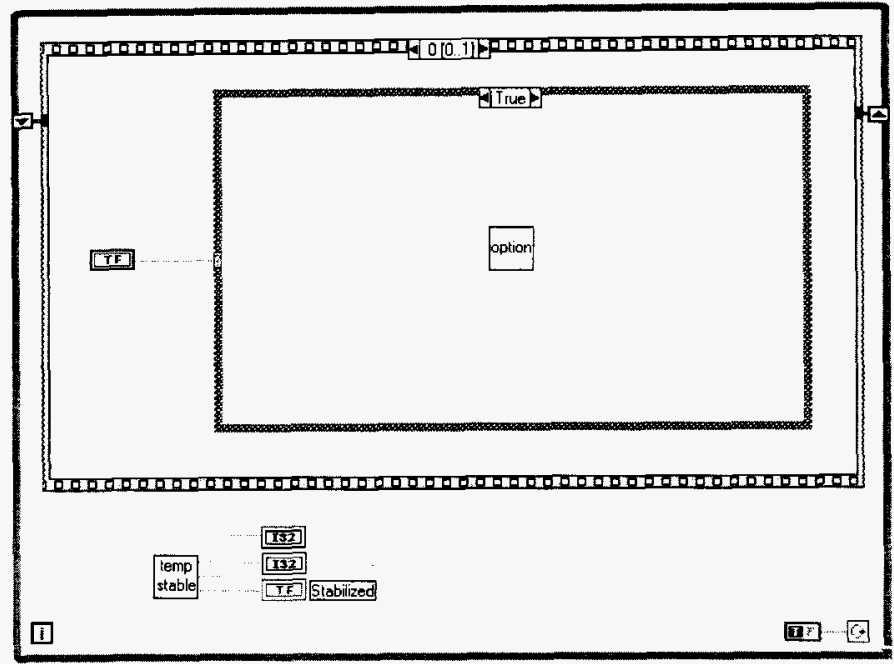

Figure 2 Main Loop

\subsubsection{Update Temperature Event}

This event continually updates the temperature readouts and the temperature stabilized indicator light. This is accomplished by calling the subVI, Temperature Stabilized.vi which is located in the DAQPad.llb library.

\subsubsection{Control Button Event}

This event is comprised of two sequence frames, frame 0 checks the state of the "Options" control icon, and frame 1 checks the state of the "Take Measurement" icon.

\subsubsection{Options Event}

Figure 2 shows that if the "Options" control is asserted (the user clicks on it), the subVI, Options Screen.vi (see Figure 3) is called. The Options Screen.vi is located in the Misc.llb library. If the "Options" control is not asserted no action is taken and the program continues to the next frame.

\subsubsection{Take Measurement Event}

If the "Take Measurement" icon is not asserted, the software will update the position displays on the front panel (Figure 4). This way the front panel will show current position data except for when a measurement is being taken. No movement is to take place while taking measurements. 


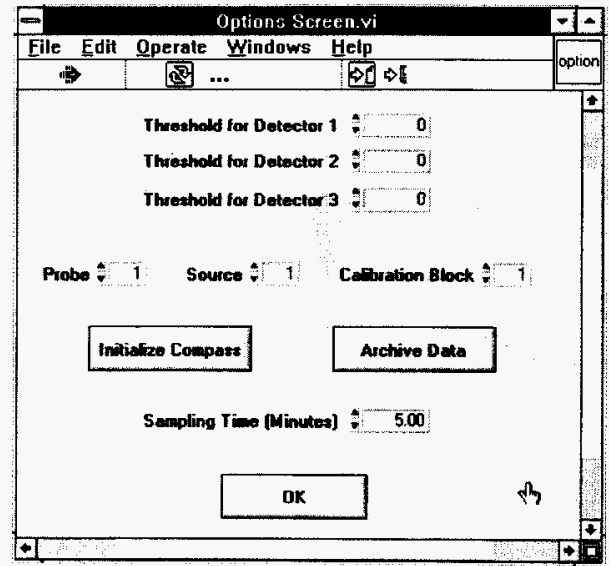

Figure 3: Options Screen

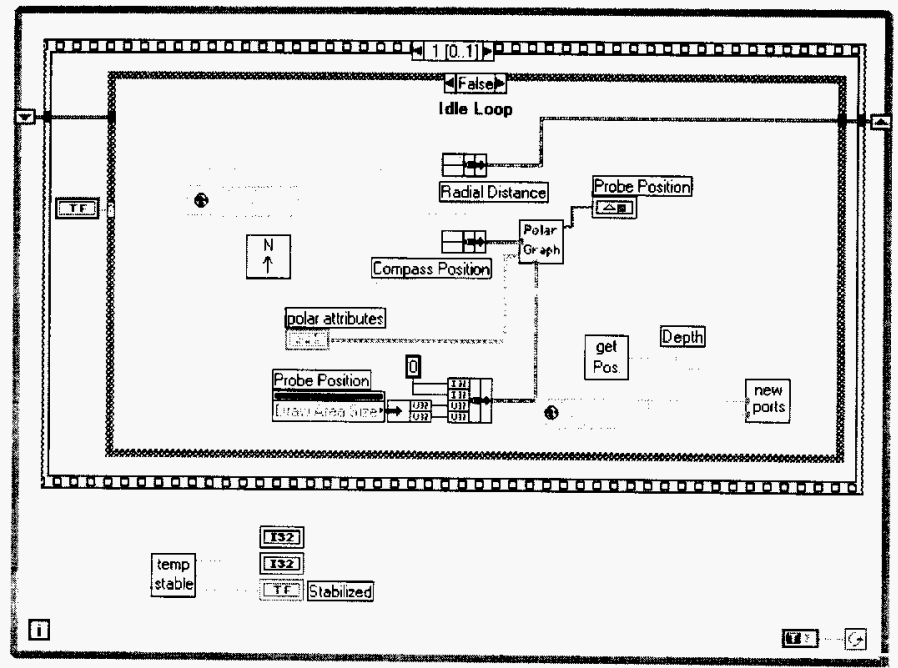

Figure 4 Position Data Update 
When the "Take Measurement" control is asserted, the software executes another set of 12 sequence frames. The first of these frames (frames begin numbering with 0 ), shown in Figure 5, initializes the counts per minute displays to zero and creates a file on disk. The inputs to the subVI, Create File.vi, are the most recent position data and the mode of data acquisition. The mode of data acquisition is determined by the front panel setting of the control "Op Check/Measurement". SubVI Create File.vi is located in the File.llb library.

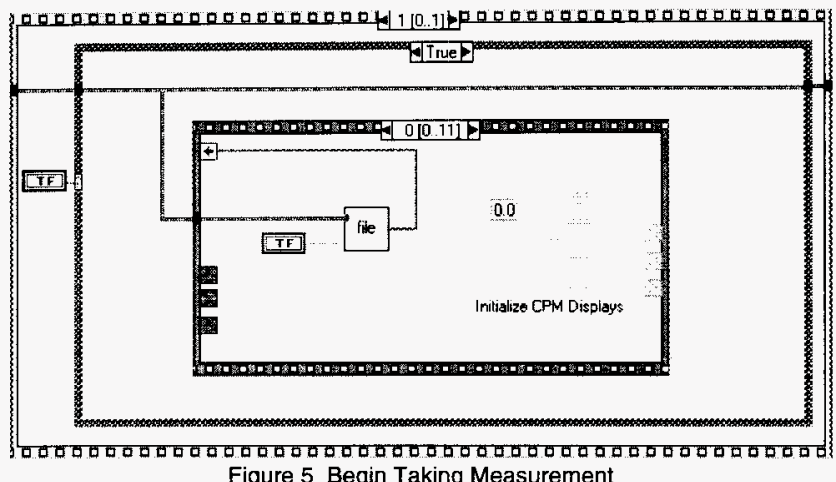

The next frame, shown in Figure 6 writes the first temperature of the probe, which is a global variable, to the newly created data file.

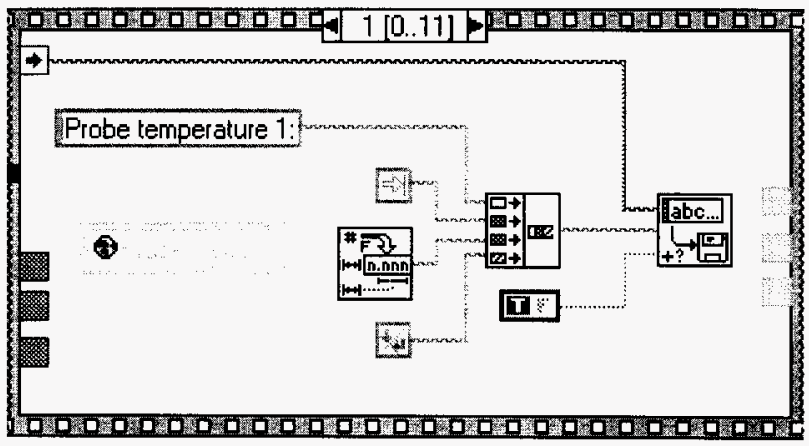

Figure 6 Write First Probe Temperature to File 
Frame 2, shown in Figure 7, writes the second probe temperature, which is a global variable, to the data file.

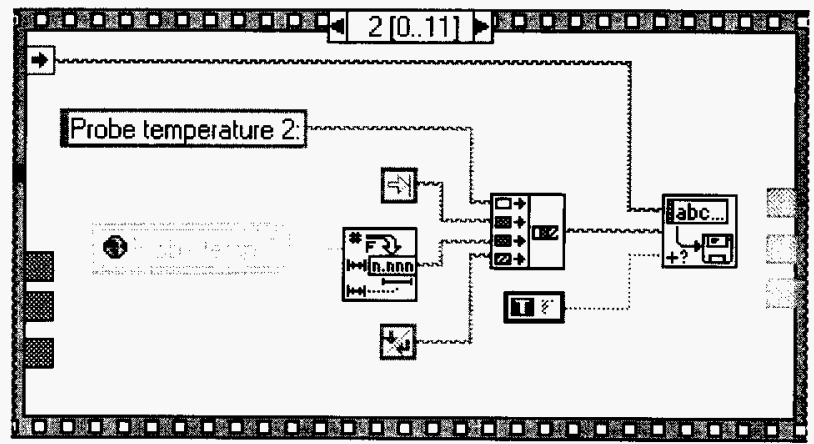

Figure 7 Write Second Probe Temperature to File

Frame 3 begins each of the three detectors counting pulses by calling Start Counting.vi which is located in the NIMBIN.llb library. Figure 8 shows the frame with another sequence frame inside. Each of the three detectors must be started separately to prevent instruction conflicts. The inside sequence frame is repeated for detectors two and three as shown in Figure 9.

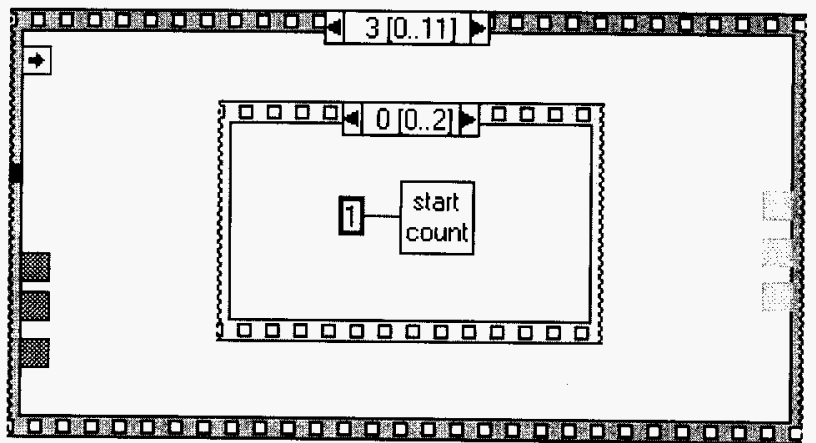

Figure 8 Begin Counting Pulses 


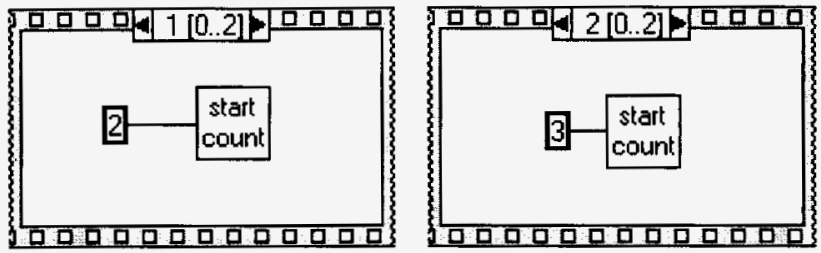

Figure 9 Start Detectors Two and Three

After the counting has started progress bars are displayed to provide feedback to the operator. This is shown in Figure 10 and makes use of subVI, Progress Bar.vi, which is located in NIMBIN.llb library.

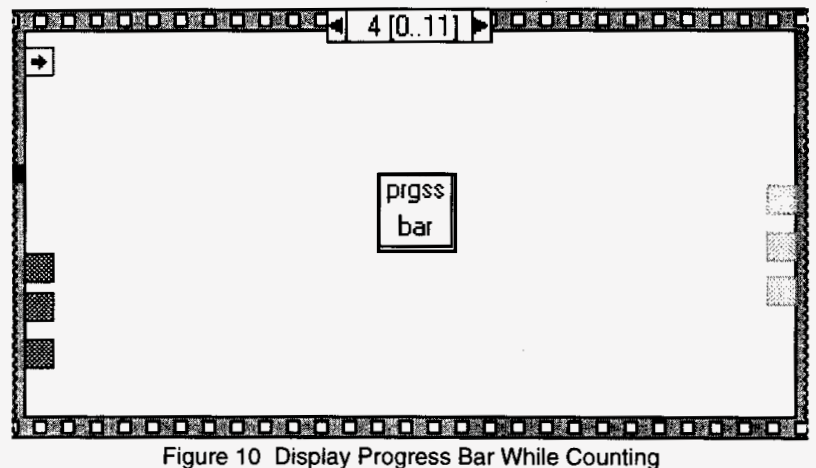

Next the count data from each of the three detectors is written to the data file and the count per minute data is displayed on the computer screen. Figures 11, 12 and 13 show this for each detector. The count data is obtained from the subVI, Get Spectrum.vi, which is located in NIMBIN.11b library. 
Rev. 0

Page 16 of 80

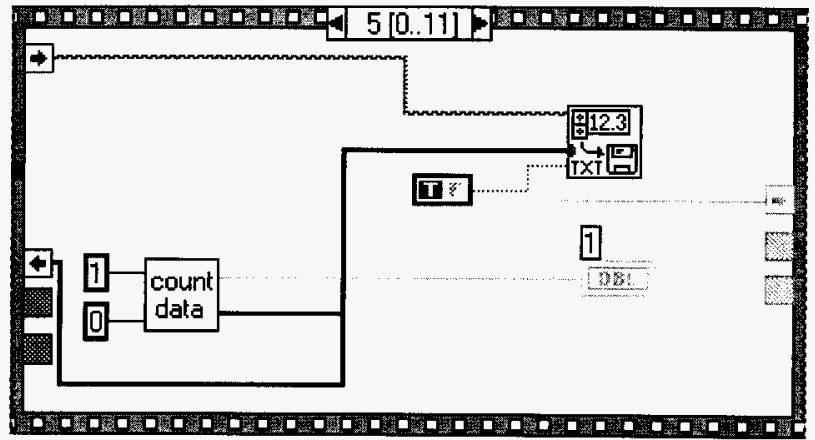

Figure 11: Write Data from Detector 1 to File

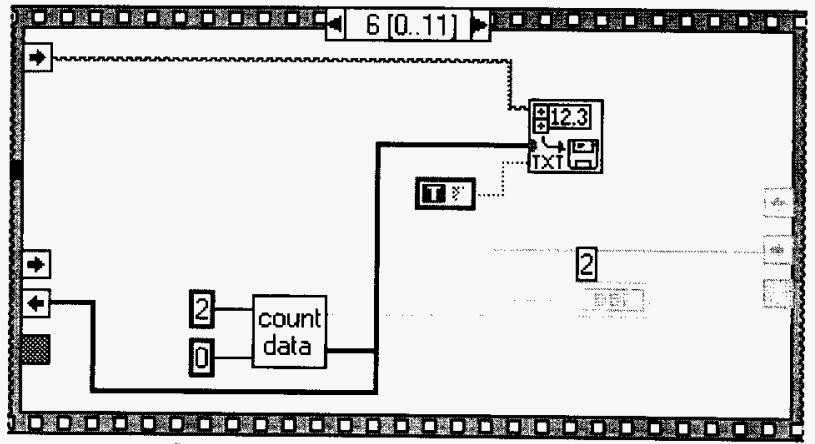

Figure 12: Write Data from Detector 2 to File

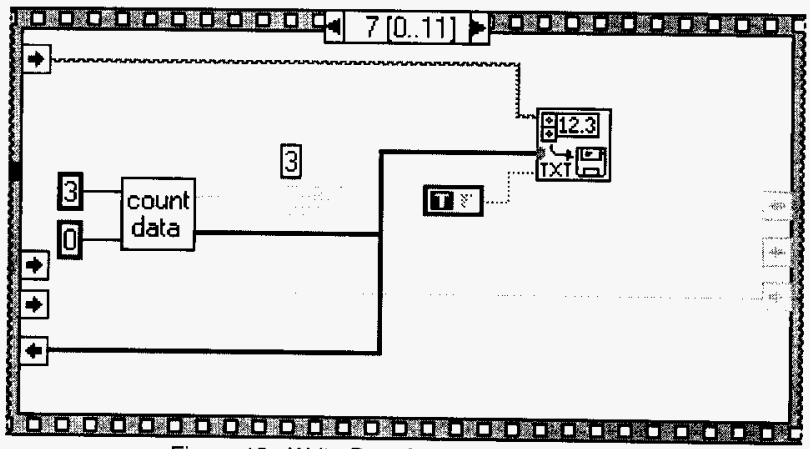

Figure 13: Write Data from Detector 3 to File 
Rev. 0

Page 17 of 80

Frame 8 shows the command to display the spectrum data on the user interface screen for all three detectors.

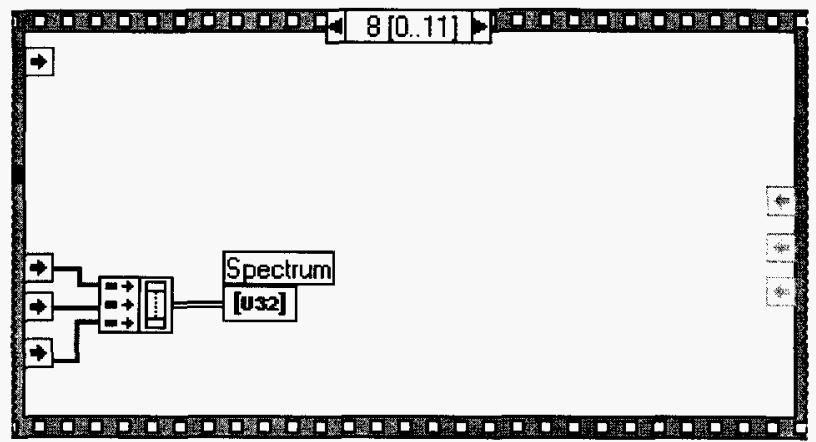

Figure 13: Display Spectrum on Screen

Finally the counts per minute is written to file for each of the three detectors as shown in Figures 15, 16 and 17.

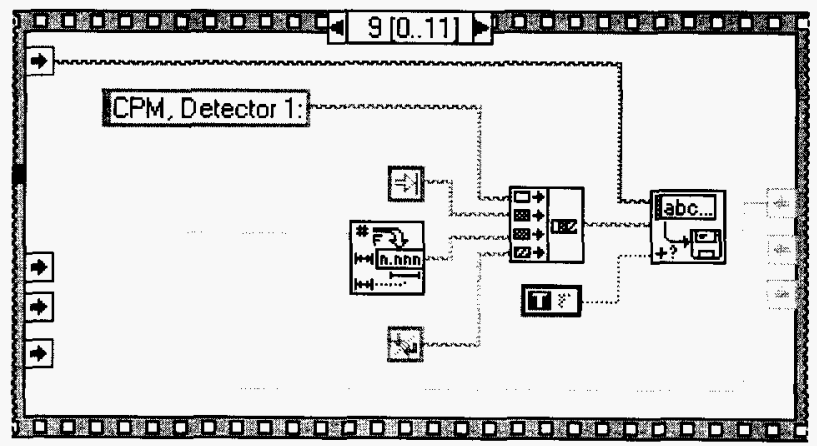

Figure 15: Write Counts Per Minute for Detector 1 


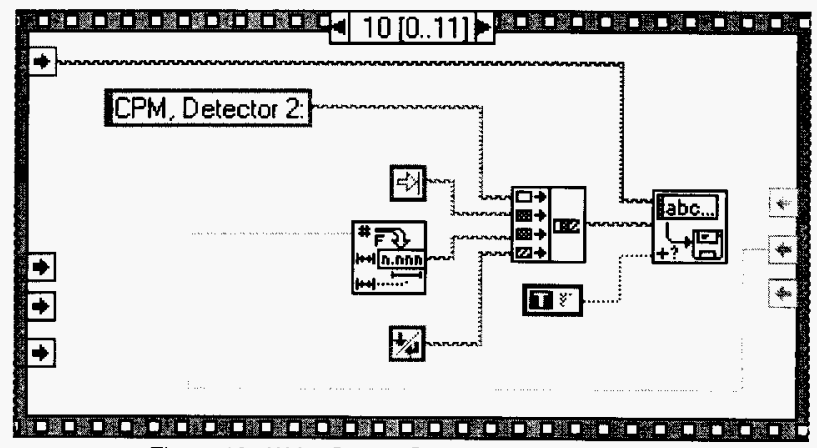

Figure 16: Write Counts Per Minute for Detector 2

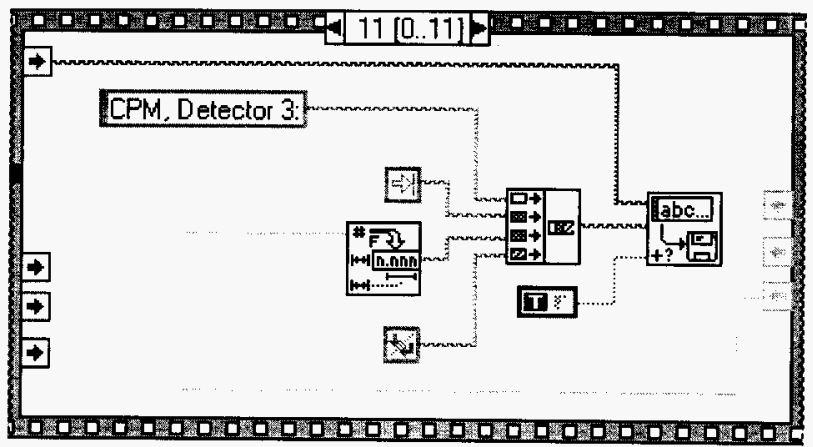

Figure 17: Write Counts Per Minute for Detector 3 


\subsection{SUB PROGRAMS}

The following pages contain descriptions of subVIs that were created to support the surface moisture measurement program. Each description shows the hierarchy of lower order subVIs. A connector pane shows the information that is passed to and from the subVI. Finally the block diagram shows the logic used to implement the subVI. The subVI's are grouped by library.

\subsubsection{Compass.1lb}

\subsubsection{1.}

\section{Checksum.vi}

\# cs

Position in Hierarchy

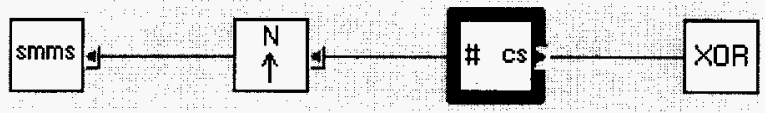

Connector Pane

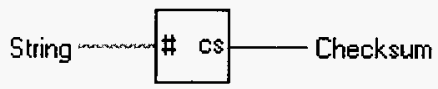

\section{Checksum.vi}

Computes the checksum of a string and returns the value in hexadecimal.

\section{Block Diagram}

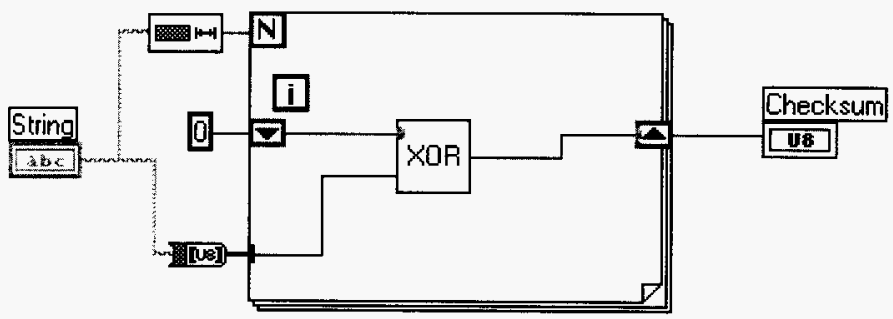


3.5.1.2. Parse String.vi

Position in Hierarchy

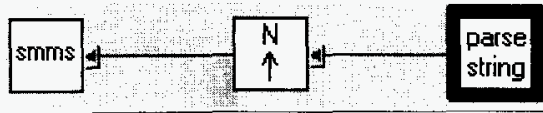

Connector Pane

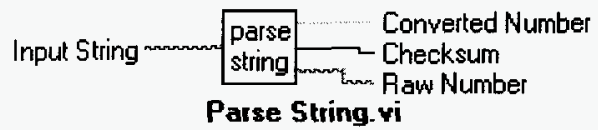

Strips the return string from the compass. The returned values are the converted number (position in degrees), the checksum value and the raw number in string format. The string format is described in TCM2 Electronic Compass Module User's Manual, Revision 1.02, Precision Navigation, Inc.

Block Diagram

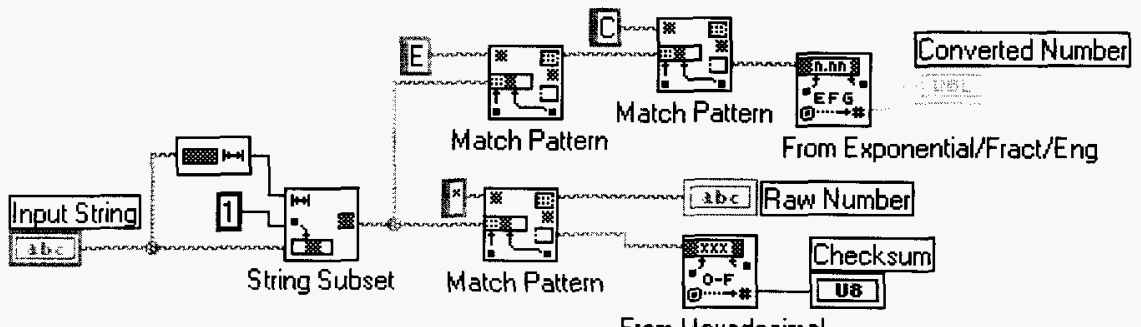

From Hexadecimal 


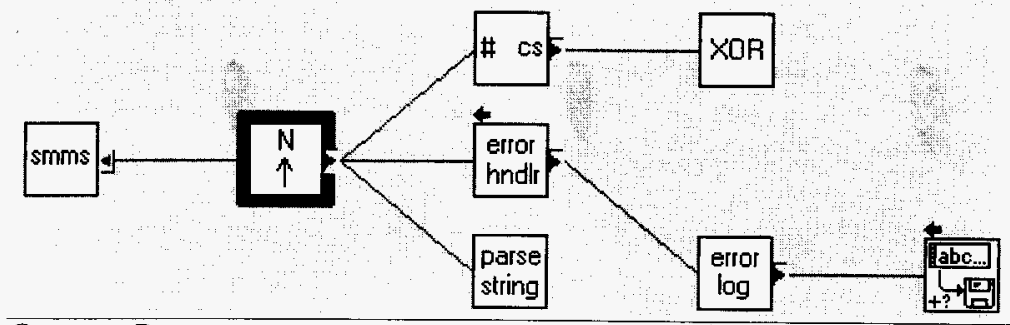

Connector Pane

\begin{tabular}{|ll}
$N$ & Display Degrees \\
$\uparrow$ & File Degrees
\end{tabular}

\section{Read Compass. VI}

This VI reads the electronic compass and returns two values. File degrees is the actual compass reading in degrees and display degrees is the reading converted to be displayed on the polar graph (zero degrees on the polar graph is east on the compass. The string format is described in TCM2 Electronic Compass Module User's Manual, Revision 1.02, Precision Navigation, Inc. Serial port parameters are COM port 1, 9.600 baud, 8 data bits, no parity, 1 stop bit.

\section{Block Diagram}

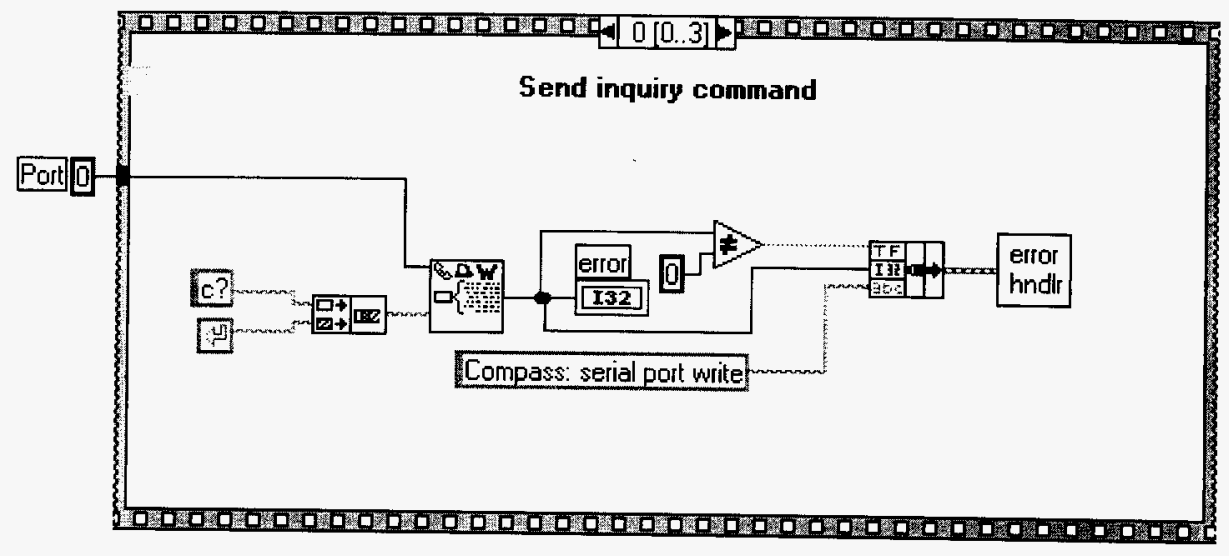




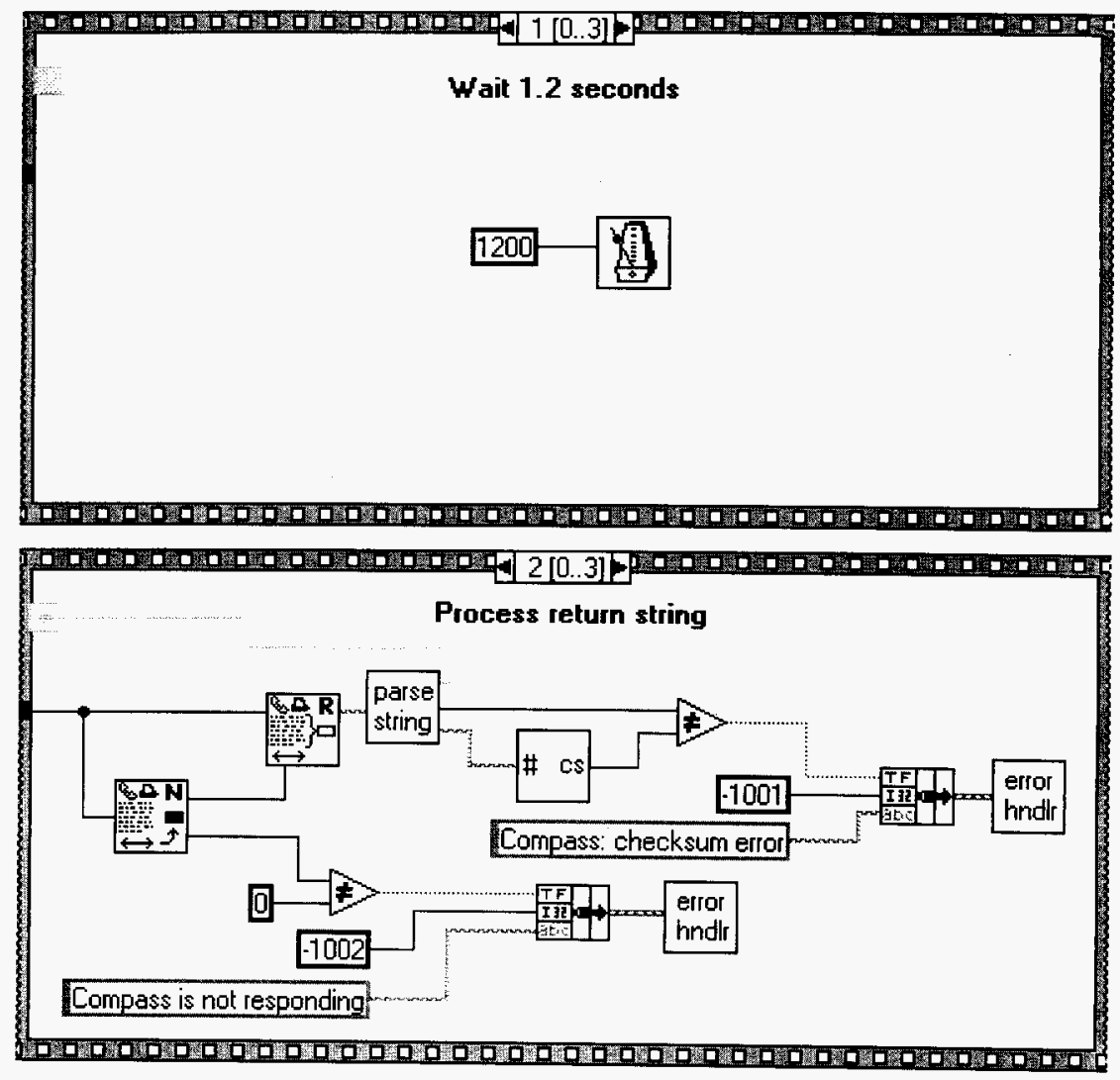


Rev. 0

Page 23 of 80
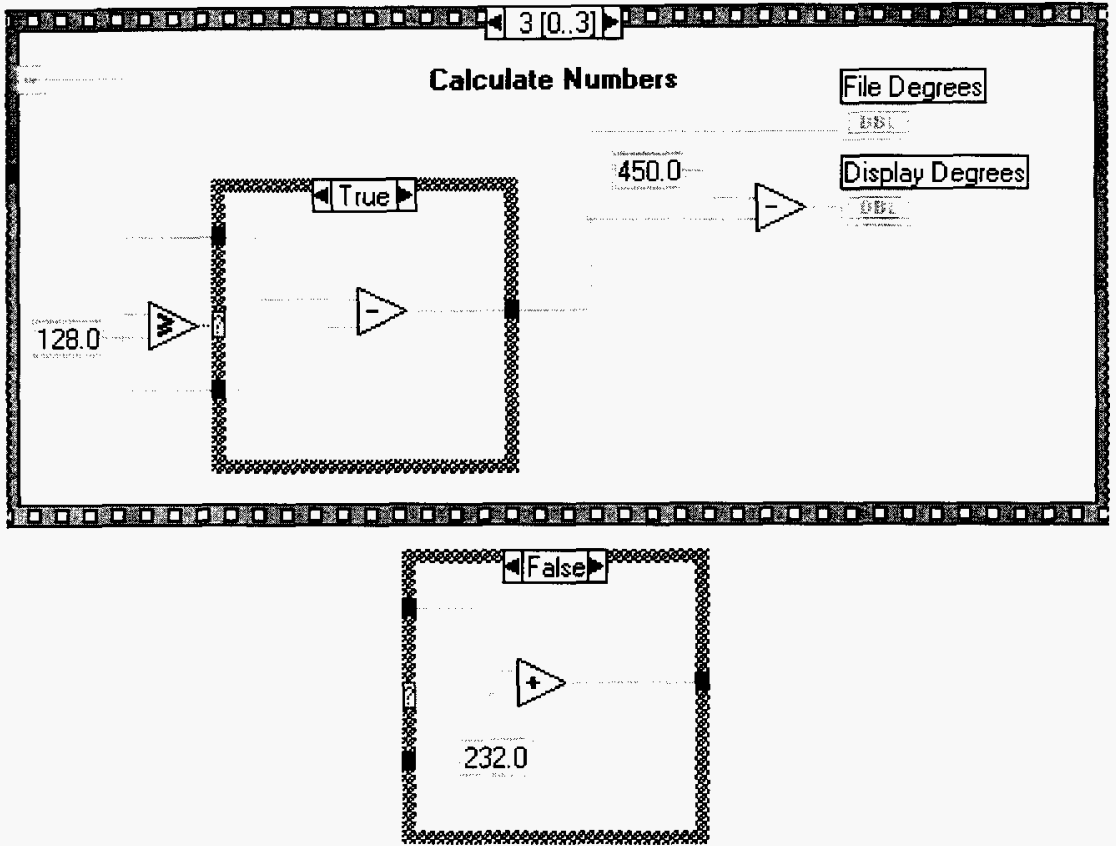

The probe position display on the front panel begins at zero degrees at the "west" position. and increases in a counter clockwise rotation. Traditional compass points, on which the data file is based, begin at zero degrees at the "north" position and increase in a clockwise rotation. The constants 450 , 232 and 128 are to calculate the two different values. 
WHC-SD-WM-CSDD-017

Rev. 0

Page 24 of 80

3.5.1.4. Send Compass Command.vi

cmps

Position in Hierarchy

and

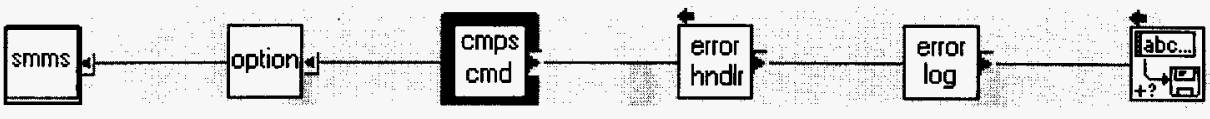

Connector Pane

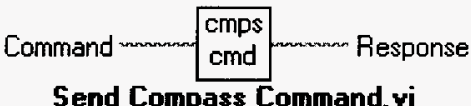

Sends a command to the compass.

Block Diagram

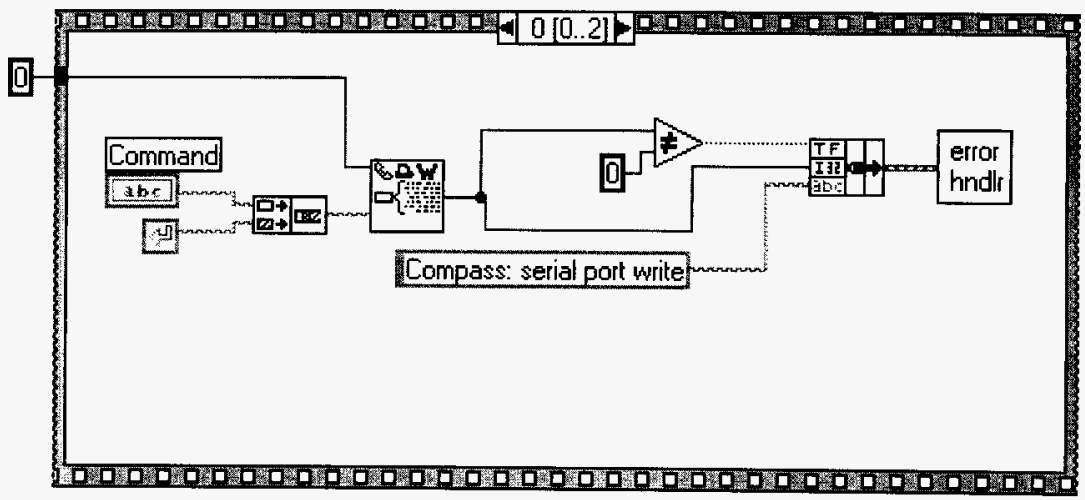




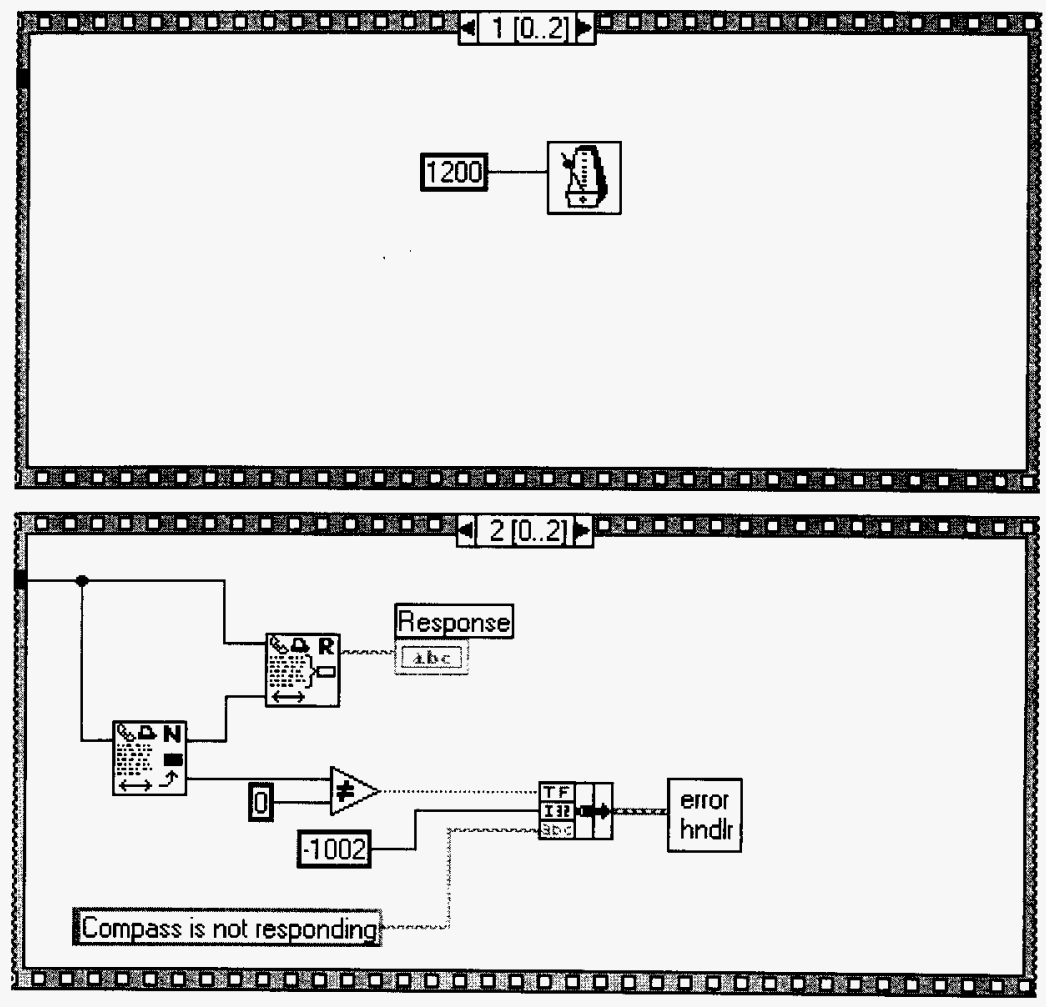


Rev. 0

Page 26 of 80

3.5.1.5. XOR Bytes.vi

$X O R$ Position in Hierarchy

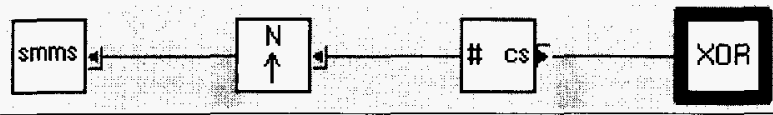

Connector Pane

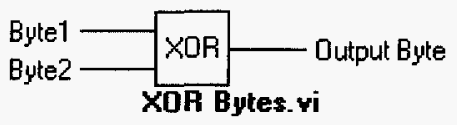

Takes two bytes and performs an exclusive OR. Returns the result as the XORed byte.

Block Diagram

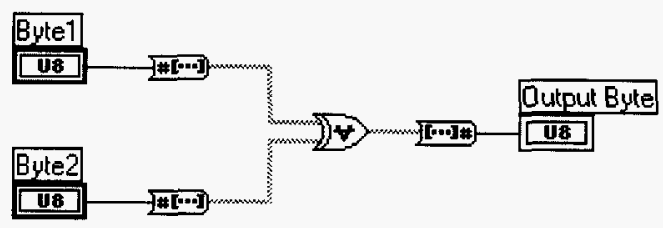




\subsubsection{DAQPad.llb}

3.5.2.1. Convert to Radial Distance.vi

Position in Hierarchy

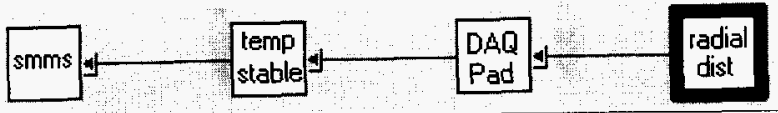

Connector Pane

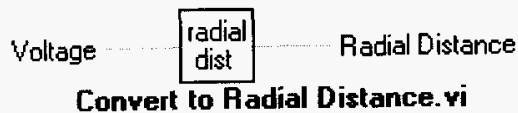

Takes a voltage and converts it to a radial distance in feet from riser centerline. The formula for the conversion is $5.7 \operatorname{Sin}\left(\frac{\pi \text { Volts }}{10}\right)$.

Block Diagram

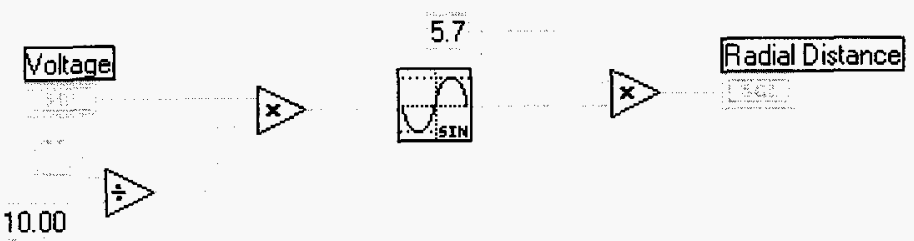


Position in Hierarchy

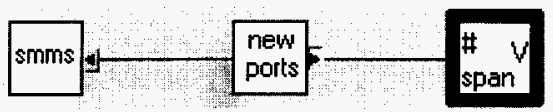

Connector Pane

$\begin{aligned} \text { Input Value } & \text { \# } \\ \text { Span } & \text { Span }\end{aligned}$

\section{Convert to Volis. vi}

Takes a value and converts it to a voltage on the scale zero to 5 volts. The input parameter, span, is the maximum value that the input parameter, Input Value, can have.

Block Diagram

Input Value

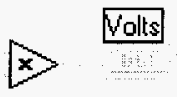

Span<smiles></smiles> 
Position in Hierarchy

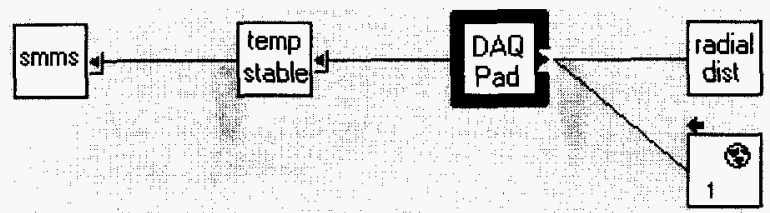

Connector Pane

\begin{tabular}{|ll}
\hline DAQ & First Temperature \\
Pad & Second Temperature
\end{tabular}

\section{Read DAQPad. vi}

This VI reads the DAQPad for analog input. There are three channels of input. Two values are output as temperatures and the inclinometer reading is stored in a global variable. The temperature transducers return a voltage in proportion to the temperature in degrees Celsius. At zero degrees Celsius, the transducers return 0 volts. At any other temperature the transducers return 0.1 volts per degree Celsius. At temperatures below zero degrees Celsius, the transducers return a negative voltage.

Block Diagram

DAQPad-1200 8 Channels 3:0 1 2 \%

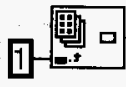<smiles>C12C3C1C23</smiles>

First Temperature
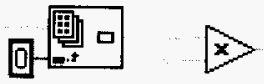

Second Temperature

10.0

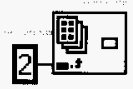

radial

dist

INC
6

READ 
WHC-SD-WM-CSDD-017

Rev. 0

Page 30 of 80

3.5.2.4. Temperature Stabilized.vi

Position in Hierarchy

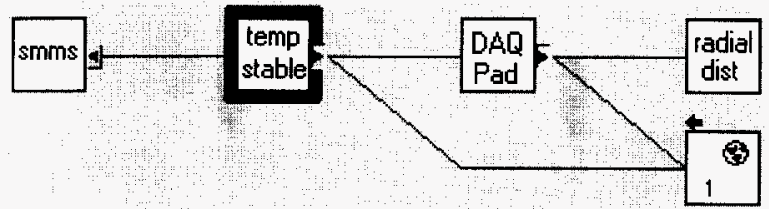

Connector Pane

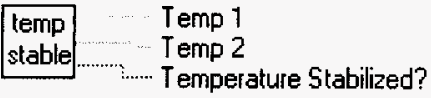

\section{Temperature Stabilized. vi}

This VI accepts two temperatures that have been read from the thermisters and outputs these values to be displayed on the front panel. Also, this VI compares these two thermister values with previously saved changing global temperature values. If the temperatures are within the specified range for a given number of seconds $(300)$, the temperature stabilized output is asserted. If the temperatures are not within the specified range, the two global temperature values are updated with the current thermister values.

Block Diagram

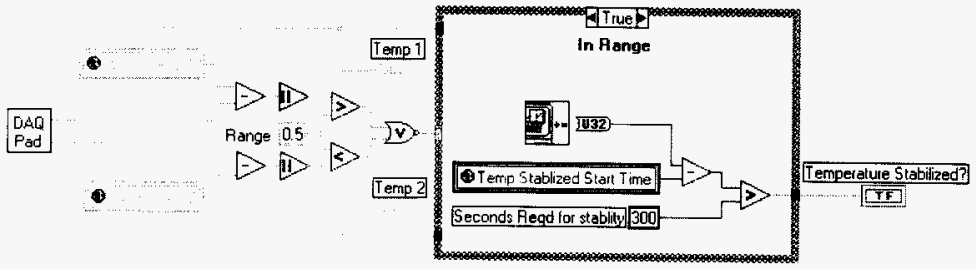


WHC-SD-WM-CSDD-017

Rev. 0

Page 31 of 80

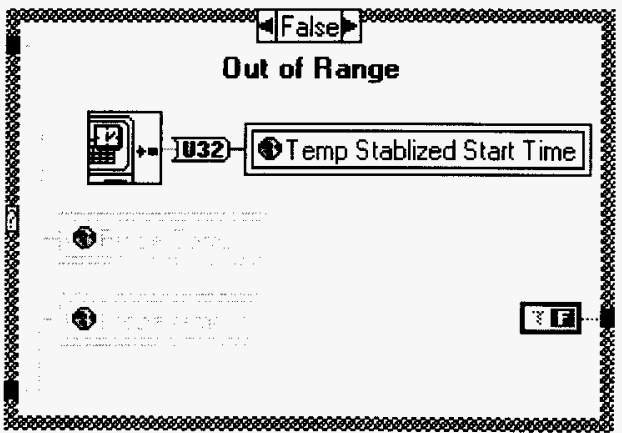


Position in Hierarchy

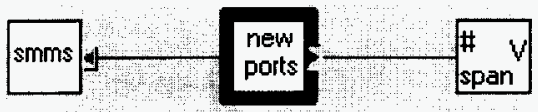

Connector Pane

\begin{tabular}{l|l} 
Compass & new \\
Encoder & ports \\
\hline
\end{tabular}

Inclinometer

\section{Update Newport meters.vi}

Takes three numerical inputs and provides an analog output voltages to drive the displays on the deployment device enclosure.

Block Diagram
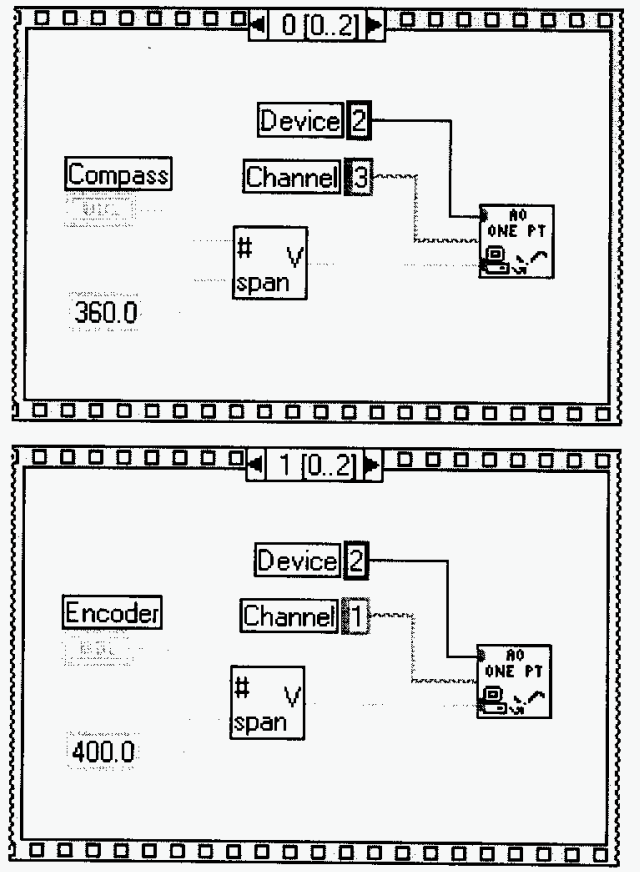
WHC-SD-WM-CSDD-017

Rev. 0

Page 33 of 80

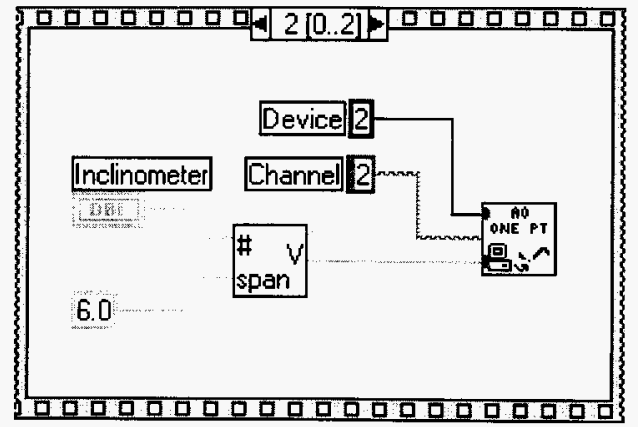




\subsubsection{Encoder.1lb}

3.5.3.1. Calculate Position.vi Position in Hierarchy

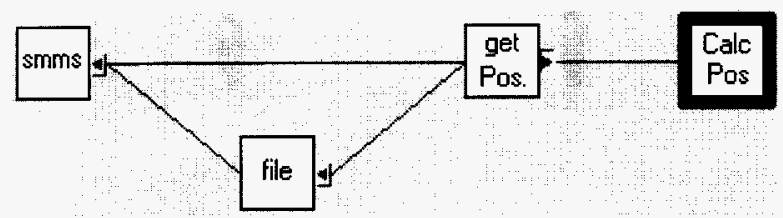

Connector Pane

Encoder Value $\longrightarrow$ Calc $\quad$ Pos ..... Position

\section{Calculate Position. vi}

Given the current encoder reading, returns the position in inches below home position. The home position value is the encoder reading when the probe is retracted to the home position. This value reflects the positioning of the encoder as installed in the deployment device. The calculation takes the current encoder position, Encoder Value, and subtracts it from the original position, Home Encoder Value, then multiplies it times the resolution of the encoder, Resolution. The resolution is determined from the encoder, 4096 positions per turn, and the drum size. The result is .000973 inches per encoder position.

\section{Block Diagram}

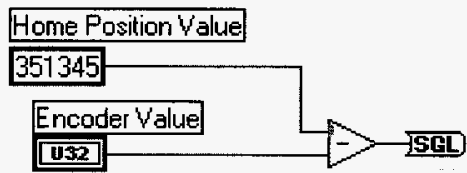

Position

Resolution 0.0009730
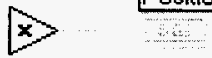
Rev. 0

Page 35 of 80

3.5.3.2. Read Encoder.vi

Pos.

\section{Position in Hierarchy}

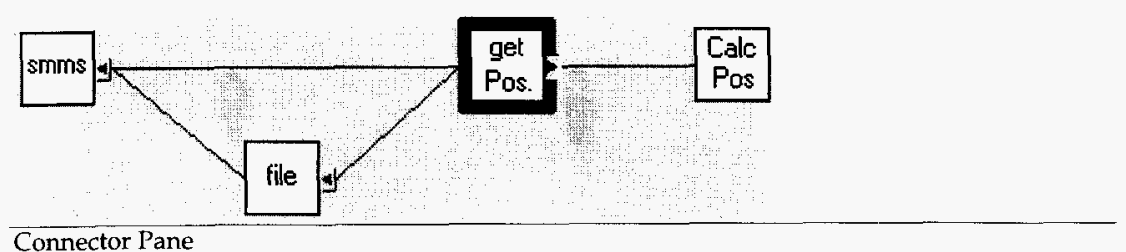

Connector Pane
get
Pos.
Position

\section{Read Encoder. yi}

Reads the encoder and returns the current depth of the probe in inches.

Block Diagram

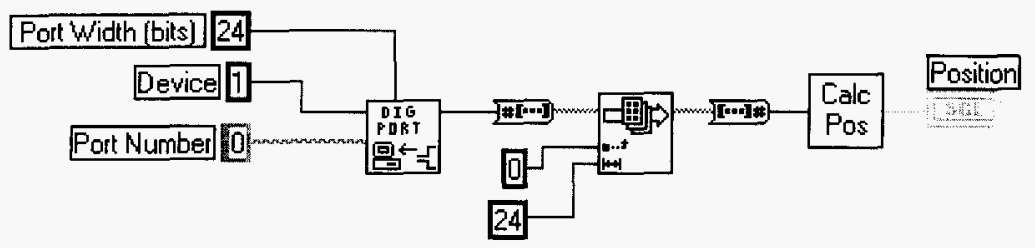




\subsubsection{Error.Ilb}

3.5.4.1. Error Handler.vi

Position in Hierarchy

hndlr

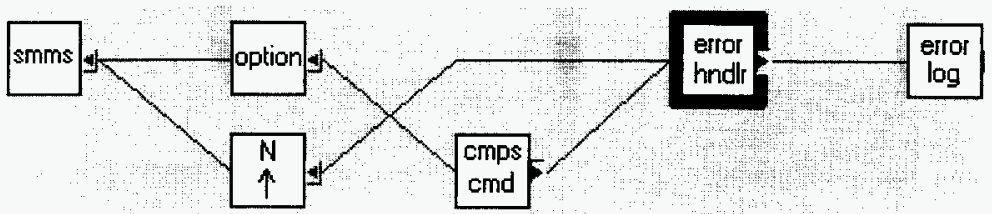

Connector Pane

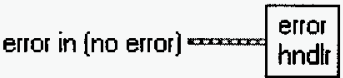

\section{Error Handler.vi}

Takes an error and displays it in an alert box. Also writes the error to the error log file by calling "Write to Error Log.vi". Refer to LabVIEW documentation for possible error codes. Block Diagram

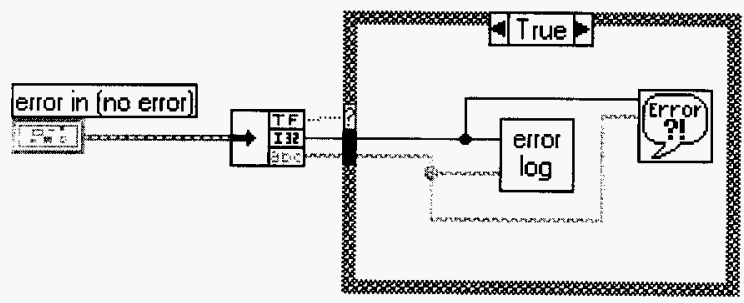




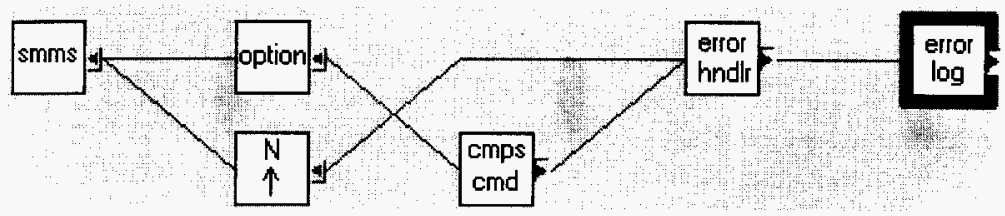

\section{Connector Pane}

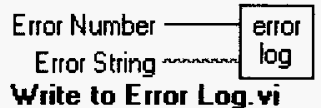

Writes error information to the error log file. The log file is automatically created if it does not exist. Each message gets appended to the existing file. Information includes a date and time stamp, error number and a text description of the error.

Block Diagram

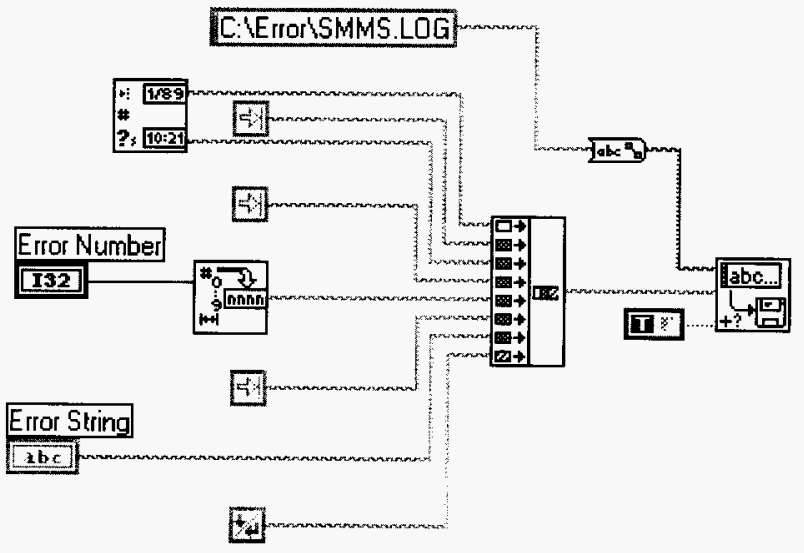




\subsubsection{File.1lb}

3.5.5.1.

Archive Files.vi

Position in Hierarchy

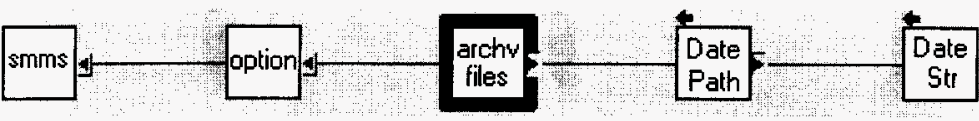

Connector Pane
archy
files

\section{Archive Files. vi}

Copies all of the current day's data files to the backup drive (D:). If this subVI cannot successfully archive the data a dialog box to that affect is presented to the user.

Block Diagram

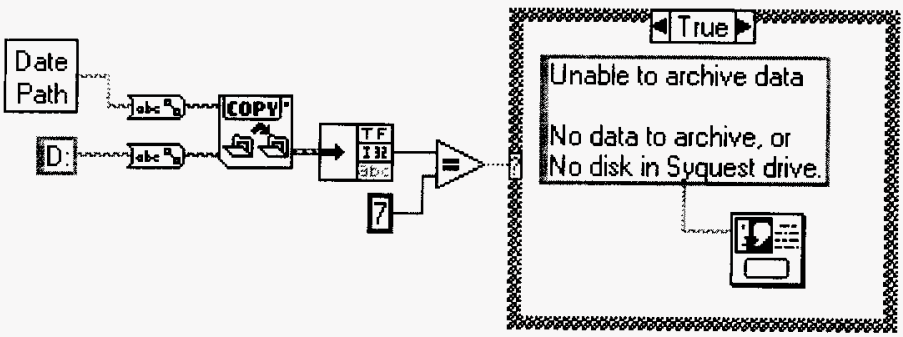


WHC-SD-WM-CSDD-017

Rev. 0

Page 39 of 80

3.5.5.2. Create File.vi

Position in Hierarchy

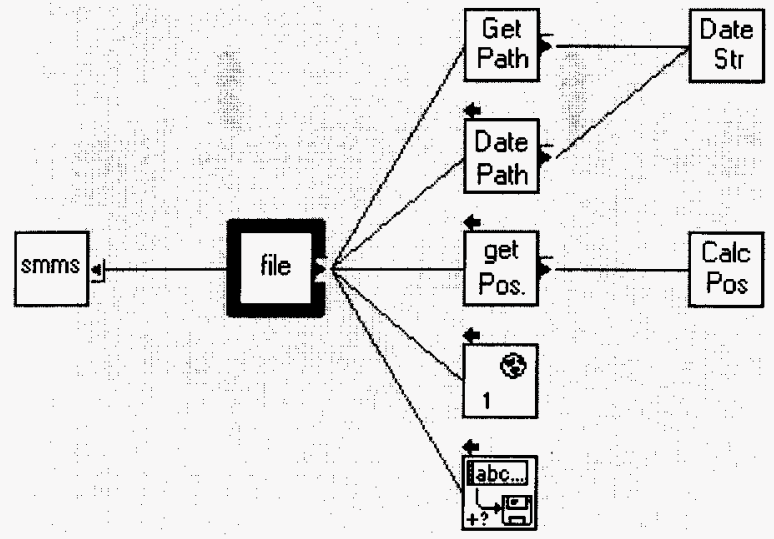

Connector Pane

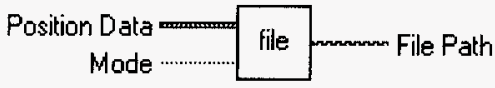

Create File. vi

Creates a new file in subdirectory "mm-dd-yy" (where "mm-dd-yy" is the current date) of directory "C: $\backslash$ DATA $\backslash S M M S \backslash$ ", writes SMMS parameters (file name, time and date stamp, program name and version, probe position, sampling time, probe number, source number and calibration block number" to the file. Returns the path to this file for future updating.

Block Diagram

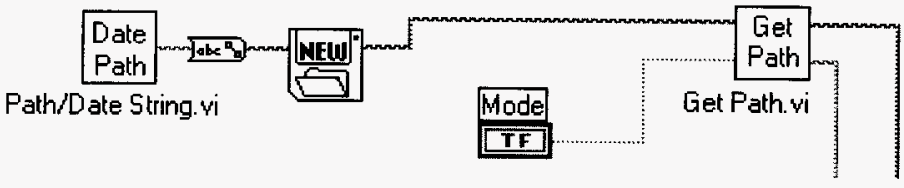



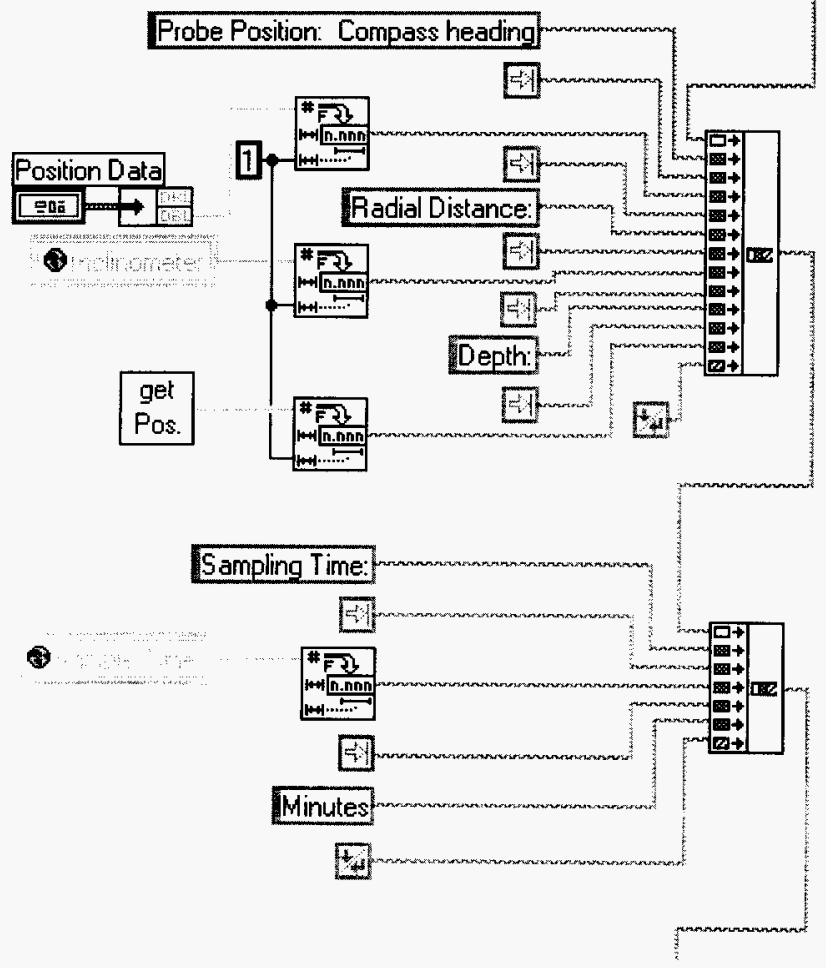
WHC-SD-WM-CSDD-017

Rev. 0

Page 41 of 80

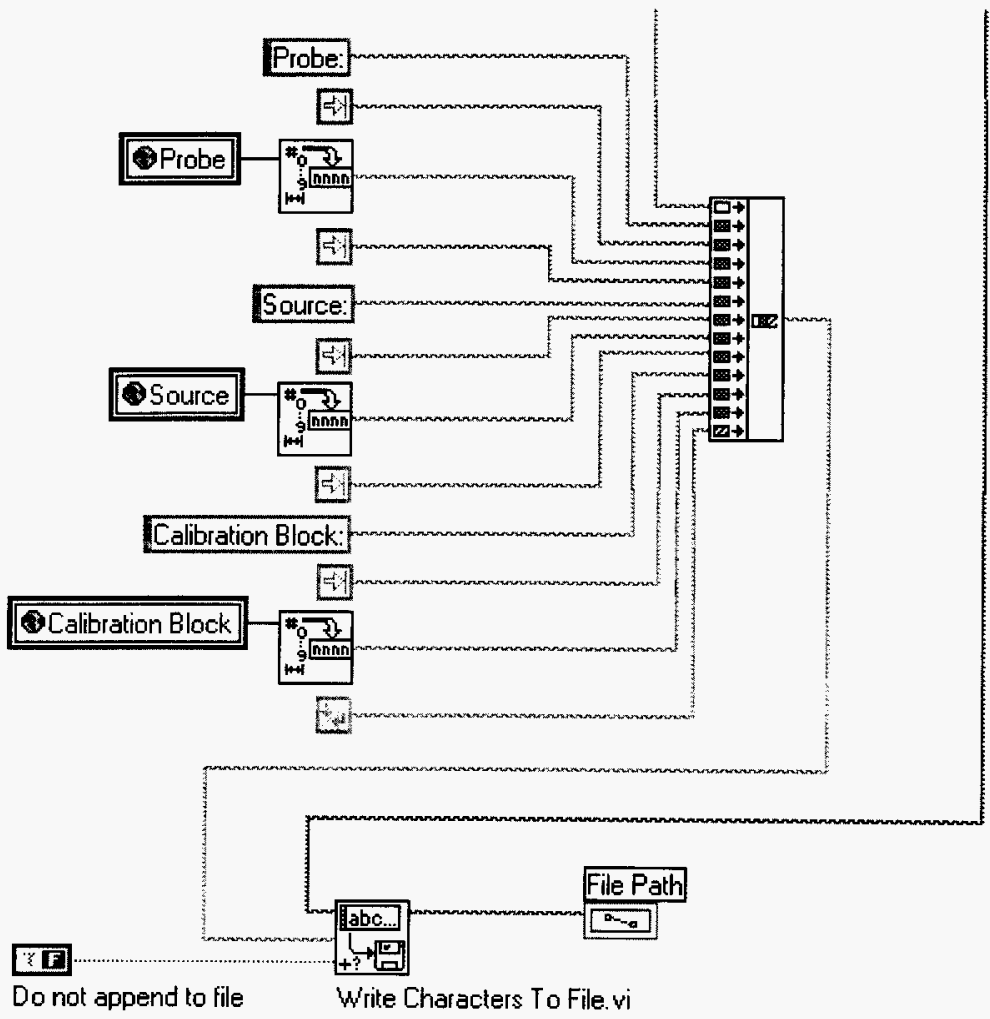




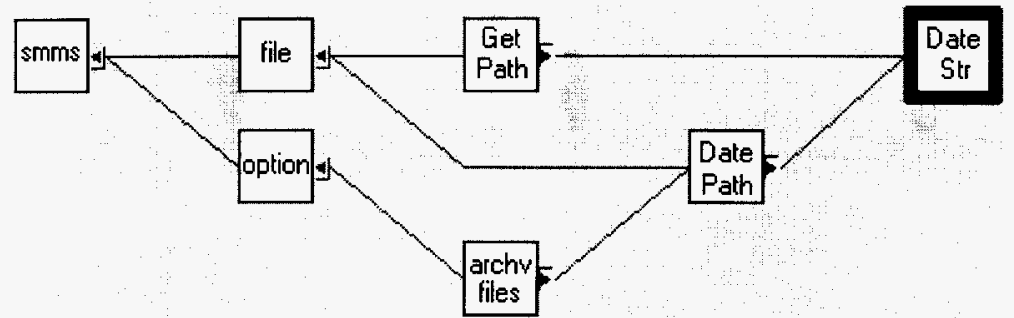

Connector Pane

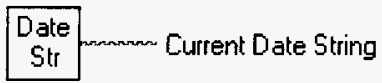

\section{Date String. vi}

Gets today's date as a string in the form of "01/01/96" and returns a string in the form "01-0196".

Block Diagram

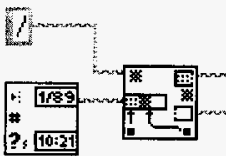

Find " $/$ "

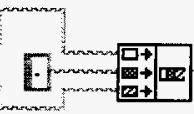

Replace with hyphen

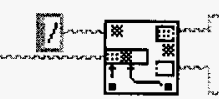

Find " $/$ "'

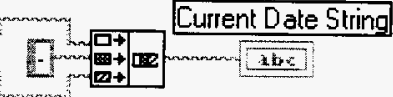

Replace with hyphen 
3.5.5.4. Get Path.vi Position in Hierarchy

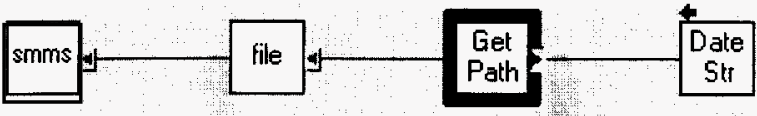

Connector Pane

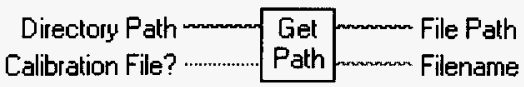

\section{Get Path.vi}

Creates a unique filename, which includes the current date, under the specified directory.

Example: "01-01-96.XXX"

Where the three digit suffix " $X X X$ " is made up of a unique three digit sequential number (Range 000 to 999 ) if not in calibration mode. If calibration mode is specified, the three digit suffix is made up of the letter " $\mathrm{C}$ " followed by a unique two digit sequential number (range $\mathrm{C} 00$ to $\mathrm{C} 99$ ). 
Rev. 0

Page 44 of 80

\section{Block Diagram}

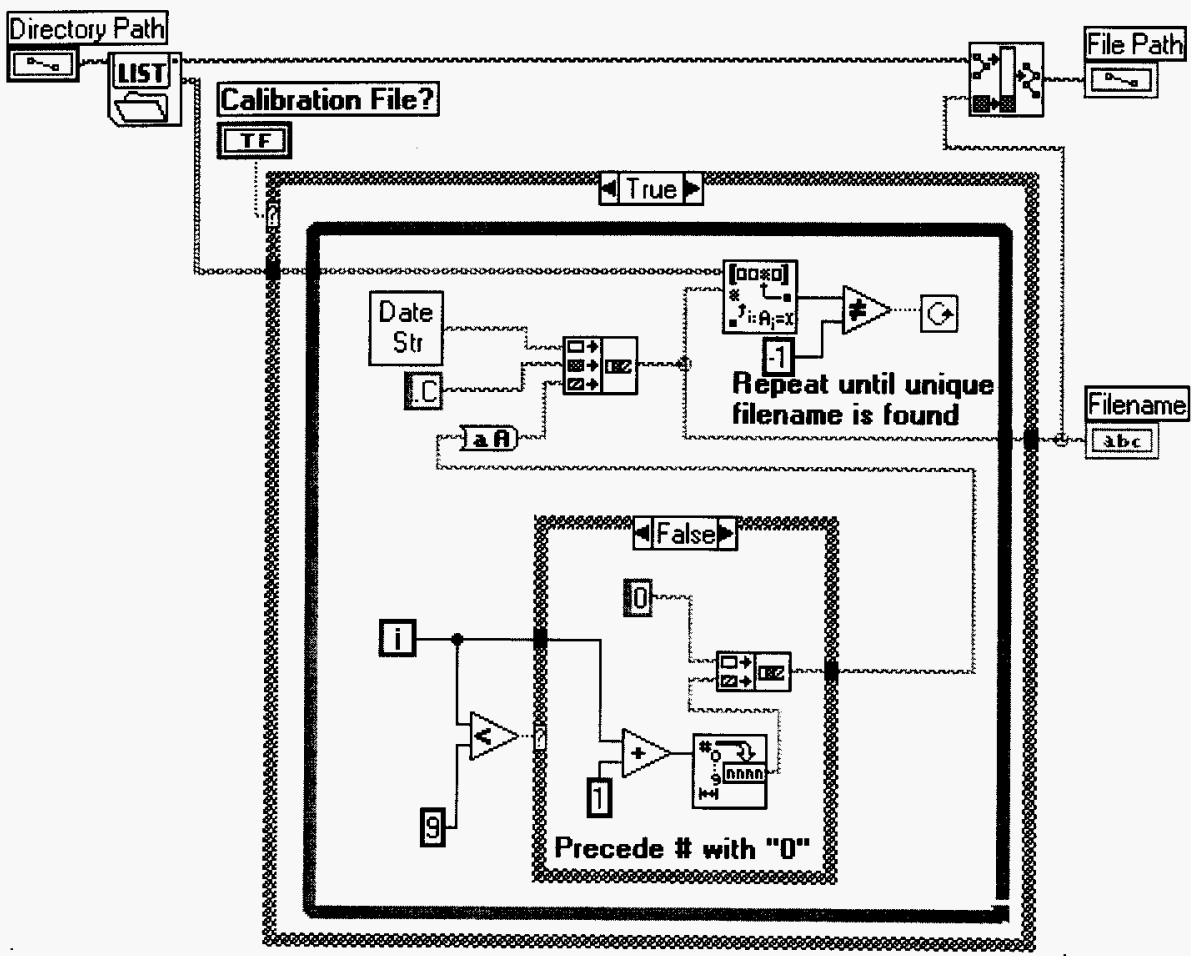



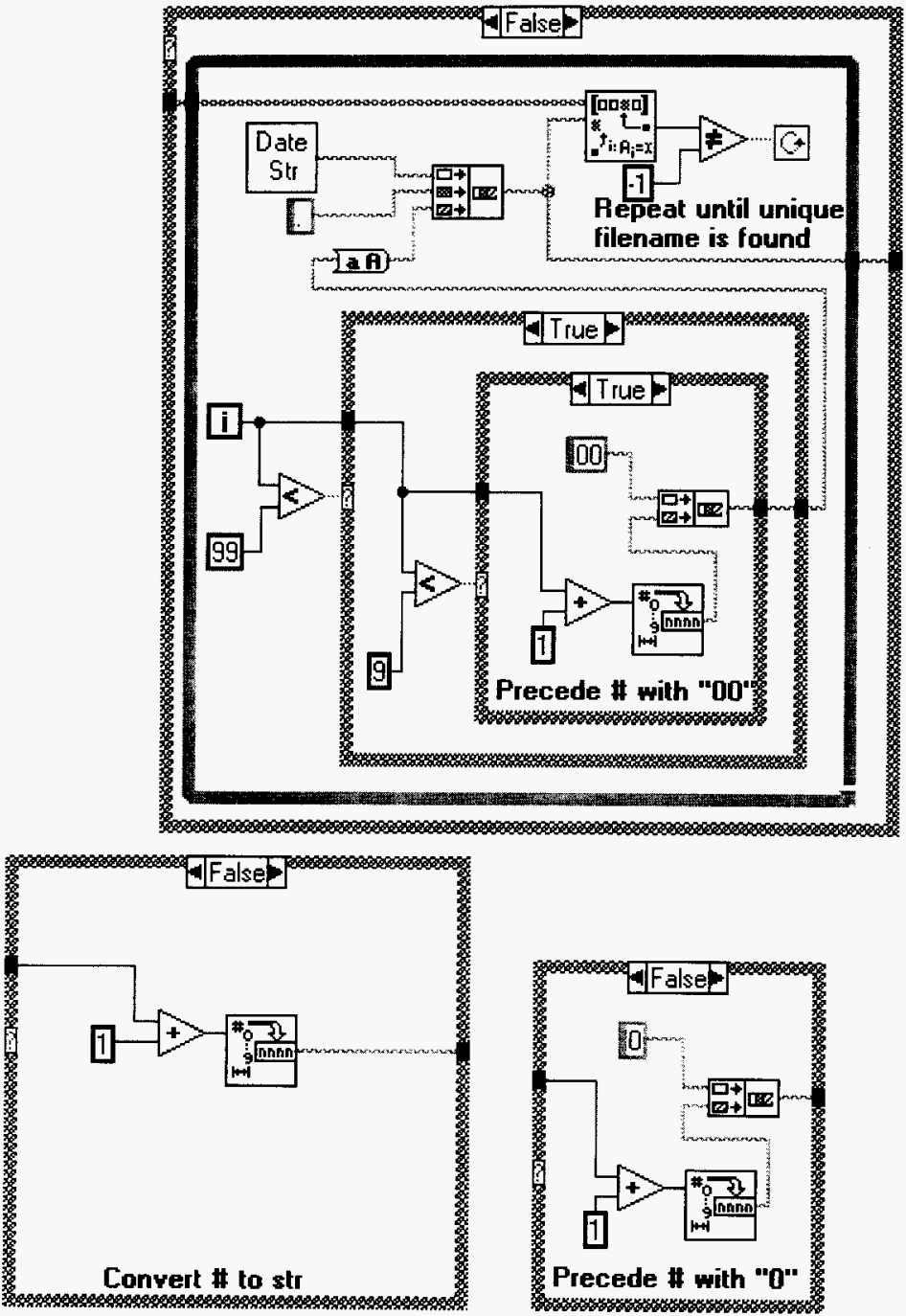
Position in Hierarchy

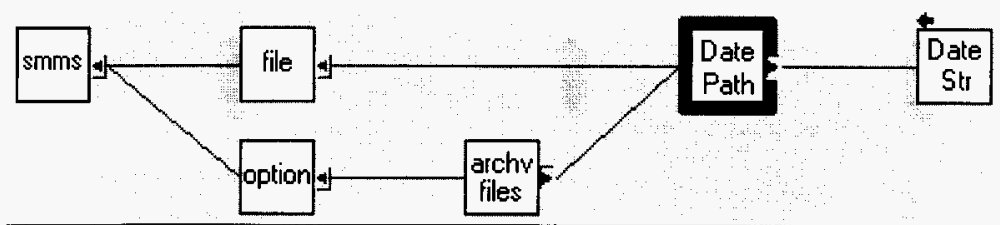

Connector Pane

\begin{tabular}{|l|} 
Date \\
Path
\end{tabular}

\section{Path/Date String.yi}

Takes a relative path and converts it to an absolute path. It does this by preceding the path with "C:\DATA \SMMS $\backslash$ ", so it is specific to this application.

Block Diagram

\section{C:LDTAISMMSY}

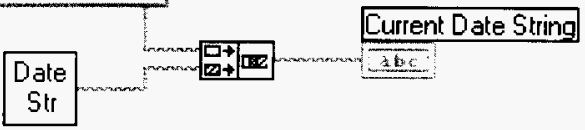




\subsubsection{Misc.1lb}

3.5.6.1. Options Screen.vi

option

\section{Position in Hierarchy}

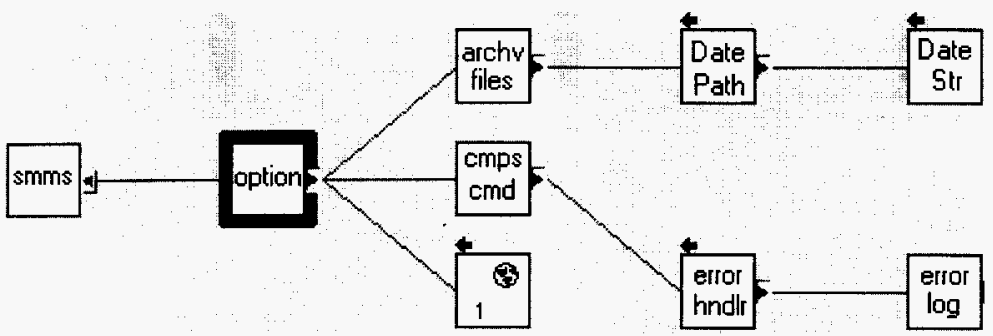

Connector Pane

Options Screen.vi

This VI presents an options screen in which the user may change parameters regarding testing, initiate a compass calibration or initiate archive data.

Block Diagram

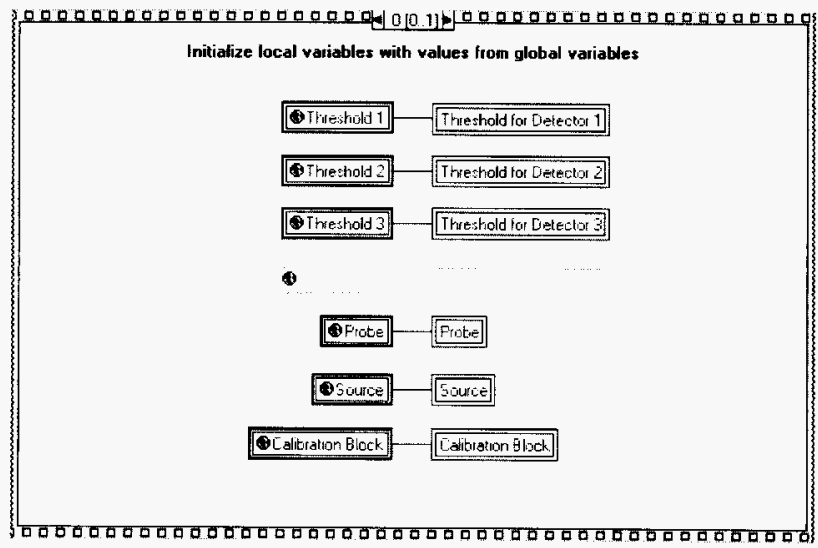

Sequence Frame 0 (first level), initializes local variables with values from the global variables. 
WHC-SD-WM-CSDD-017

Rev. 0

Page 48 of 80

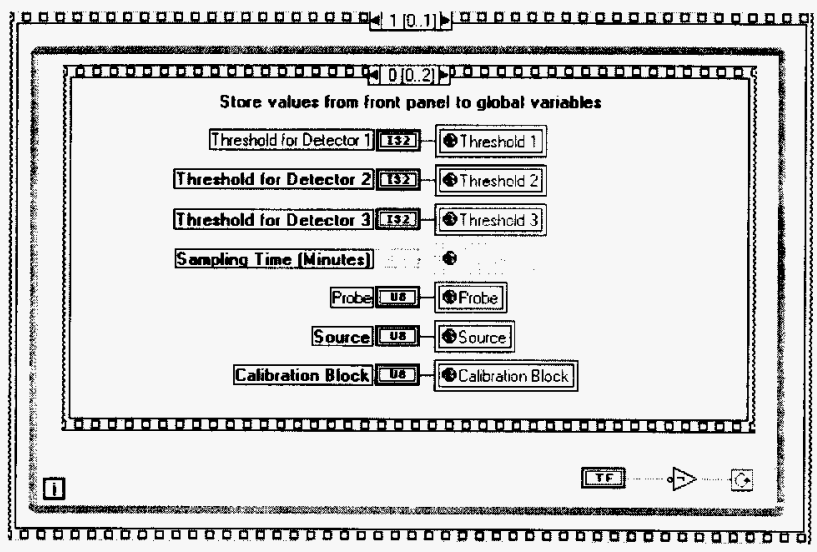

Sequence Frame 1 (first level), executes a while loop until the front panel "OK" button is asserted. Within the while loop are the three second level sequence frames.

Sequence Frame 0 (second level), stores values from the front panel to global variables.

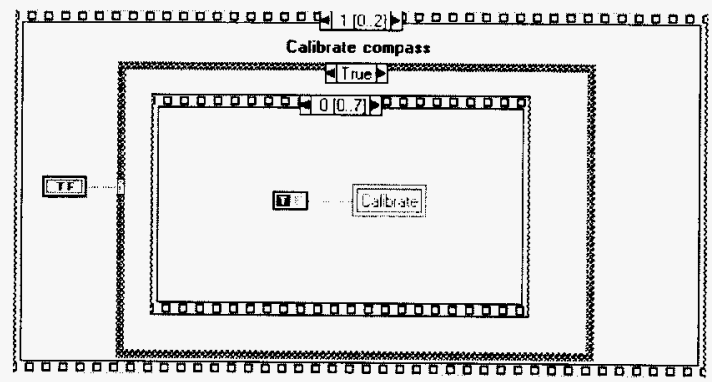

Sequence Frame 1 (second level), checks to see if "Initialize Compass" control is asserted. If not asserted, sequence frame 2 (second level) is executed. If asserted, a third level sequence of 7 frames is executed to calibrate the compass (see TCM2 Electronic Compass Module User's Manual, Revision 1.02, Precision Navigation, Inc).

Sequence Frame 0 (third level), set local "Calibrate" variable to true. 
WHC-SD-WM-CSDD-017

Rev. 0

Page 49 of 80

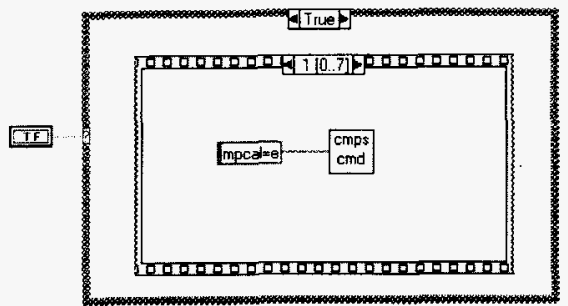

Sequence Frame 1 (third level), send string "mpcal=e" to Send Compass Command.vi.

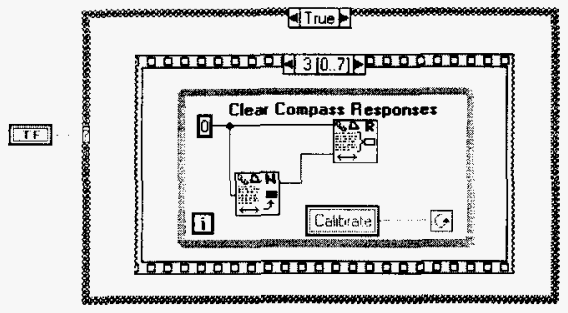

Sequence Frame 3 (third level), clear compass responses

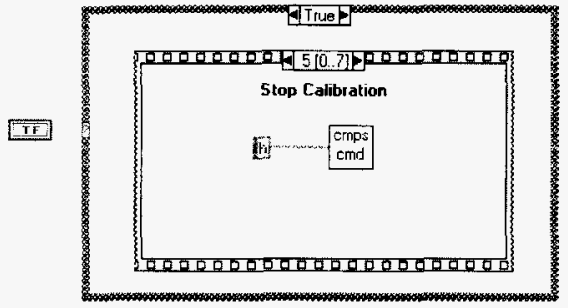

Sequence Frame 5 (third level), send string " $h$ " to Send Compass Command.vi.

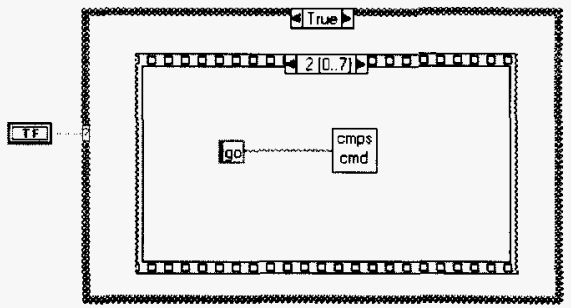

Sequence Frame 2 (third level), send string "go" to Send Compass Command.vi.

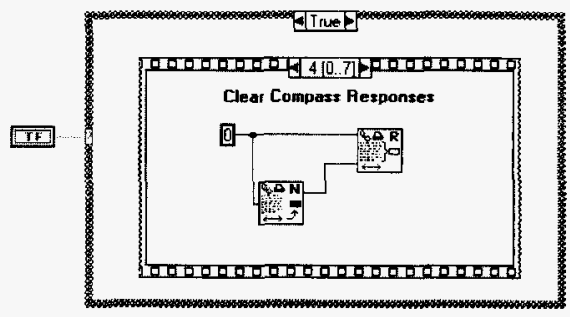

Sequence Frame 4 (third level), clear compass responses.

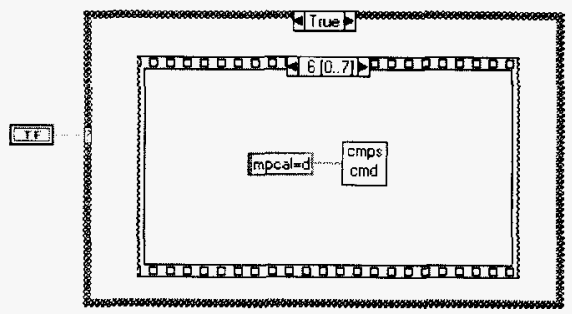

Sequence Frame 6 (third level), send string "mpcal=d" to Send Compass Command.vi. 


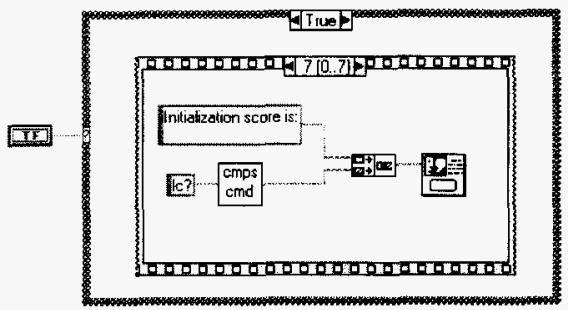

Sequence Frame 7 (third level) send string "lc?" to Send Compass Command.vi and read and display the electronic compass initialization score.

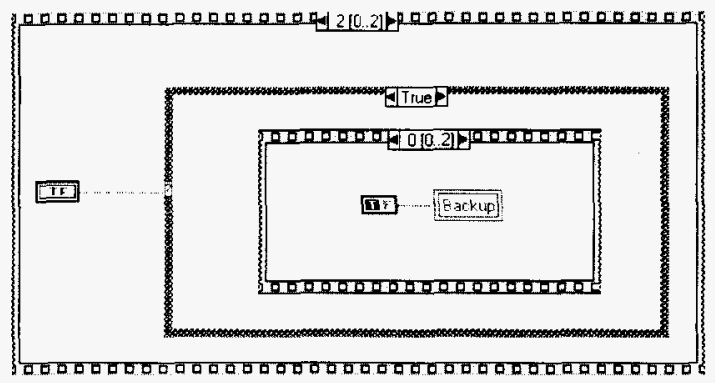

Sequence Frame 2 (second level), checks to see if "Archive Data" control is asserted. If not asserted, control is passed back to the while loop. If asserted, a third level sequence of 3 frames is executed to archive data files as follows.

Sequence Frame 0 (third level), set local "Backup" variable true.

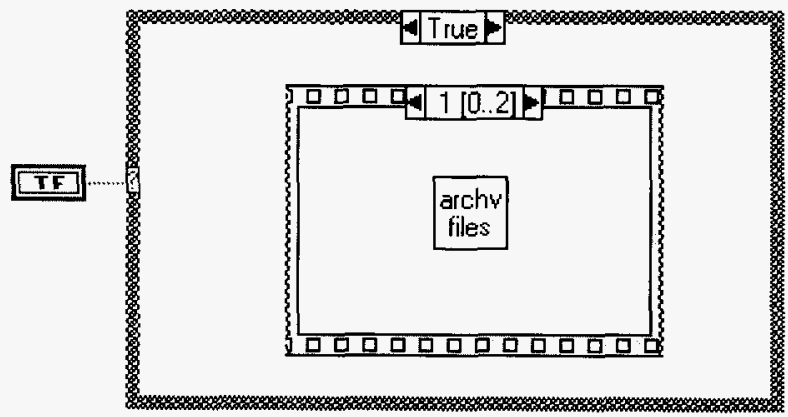

Sequence Frame 1 (third level), execute Archive Files.vi. 
WHC-SD-WM-CSDD-017

Rev. 0

Page 51 of 80

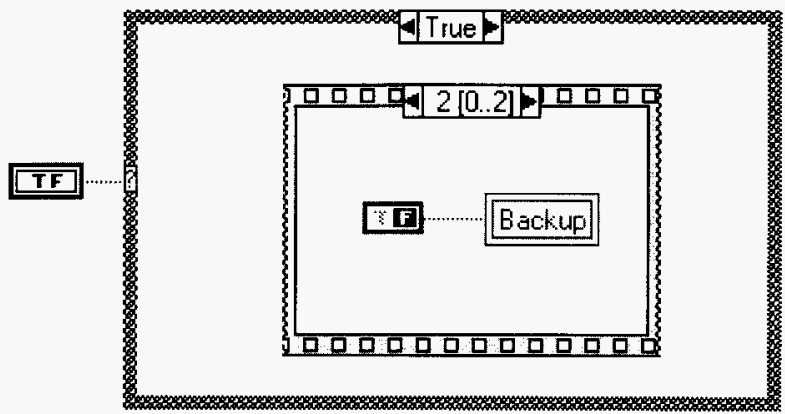

Sequence Frame 2 (third level), set local "Backup" variable false. 
Position in Hierarchy

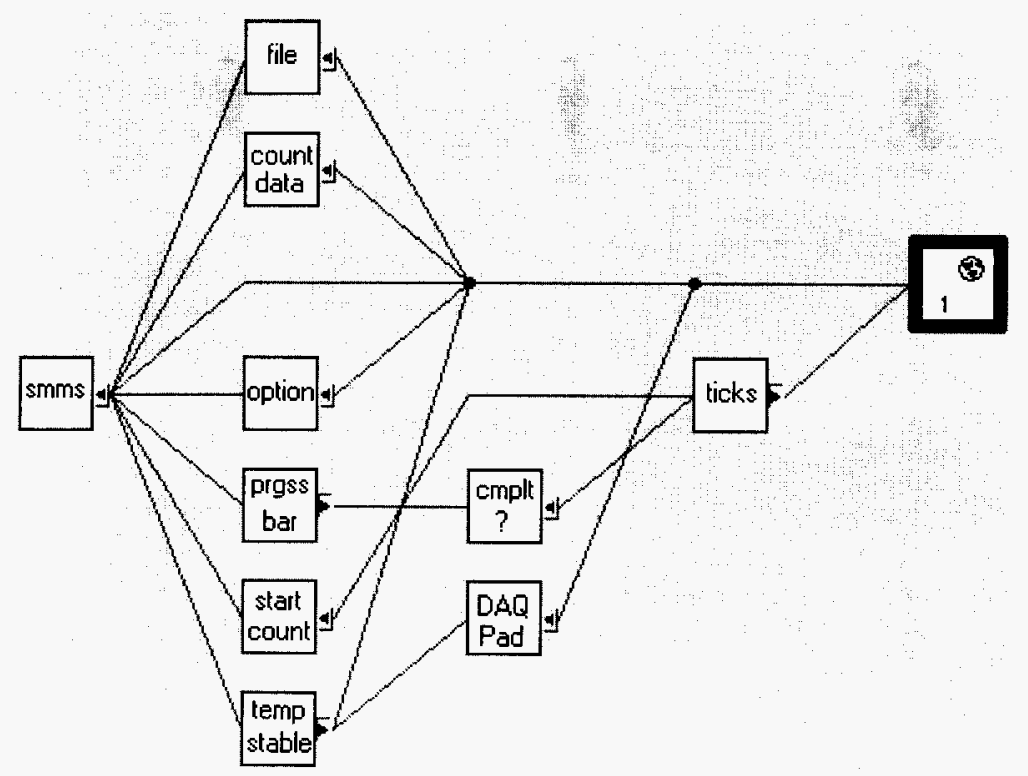

Connector Pane

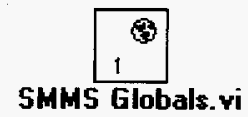

Global variables for SMMS software. 
Front Panel

Inclinometer

0.00

Temp Stablized Start Time

0
Probe Temp 1]

0.00

\section{Probe temp 2}

0.00

$$
\text { Probe }
$$

Calibration Block

\section{Threshold 1]}

o

Threshold 2

0

Threshold 3

o

Sample Time

5.00 


\subsubsection{NIMBIN.1Ib}

3.5.7.1. Check Progress.vi

Position in Hierarchy

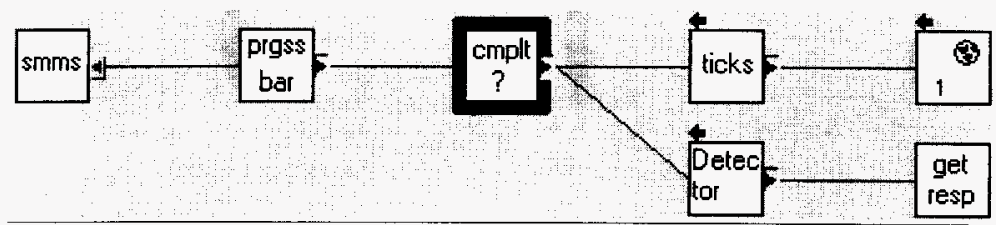

Connector Pane

Detector $-\left[\begin{array}{c}\text { cmplt } \\ ?\end{array} \quad\right.$ Percent Complete

\section{Check Progress.vi}

Makes inquiry of MCA as to the progress of the counting for the specified detector (refer to MCA user Manual) Returns a value that is the fraction complete (100 is finished).

Block Diagram

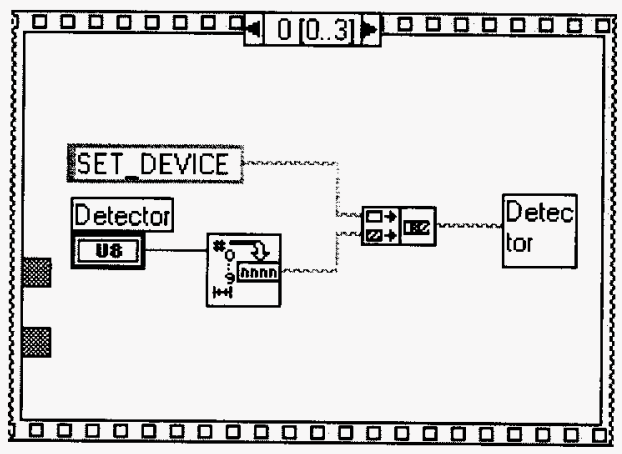

Sequence Frame 0, creates a string "SET_DEVICE" followed by the converted detector value and sends this string to "Send Command.vi". 


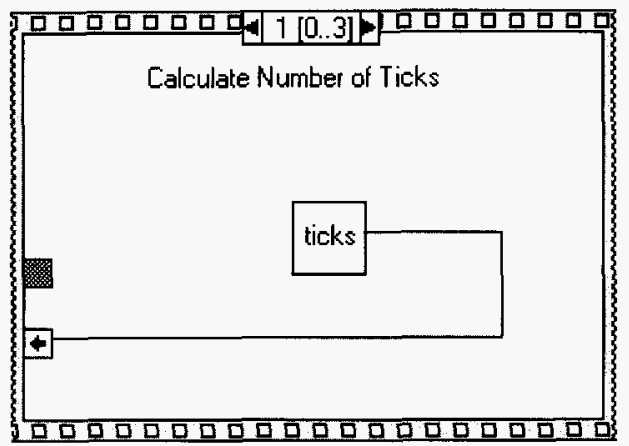

Sequence Frame 1, executes "Get Number of Ticks.vi" which returns the number of ticks equal to the global variable "Sample Time".

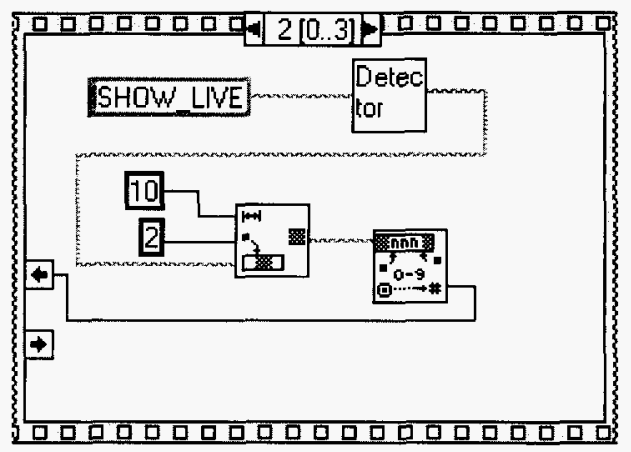

Sequence Frame 2, creates a string "SHOW_LIVE" and sends it to "Send Command.vi". Then this frame parses "Send Command.vi"'s returned string for a substring of 10 characters beginning at the offset of 2 . Next, the parsed substring is converted to a decimal integer. 
Rev. 0

Page 56 of 80

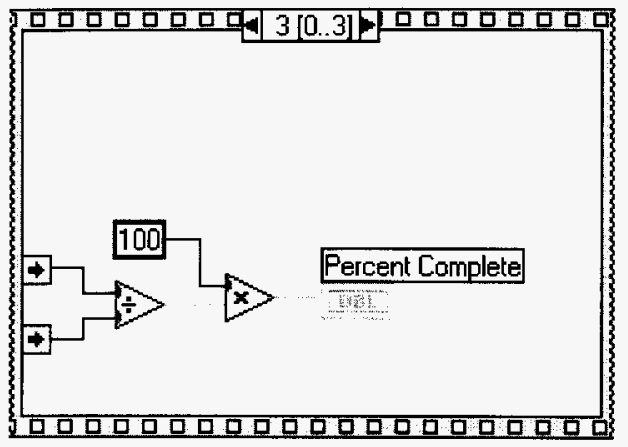

Sequence Frame 3, calculates the "Percent Complete" by dividing Frame 1's tick value by Frame 2 's integer value and then multiplying the result by 100 . 
Position in Hierarchy

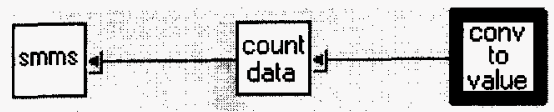

Connector Pane

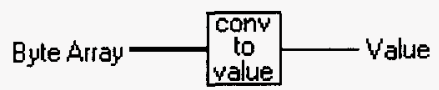

\section{Convert to Value. vi}

Converts an array of 8 bit unsigned bytes from the MCA to a 32 bit unsigned value. The value is an array of four bytes. The order of the bytes must be reversed and the most significant bit of the most significant byte must be stripped out. Refer to the MCA manual for data format.

Block Diagram

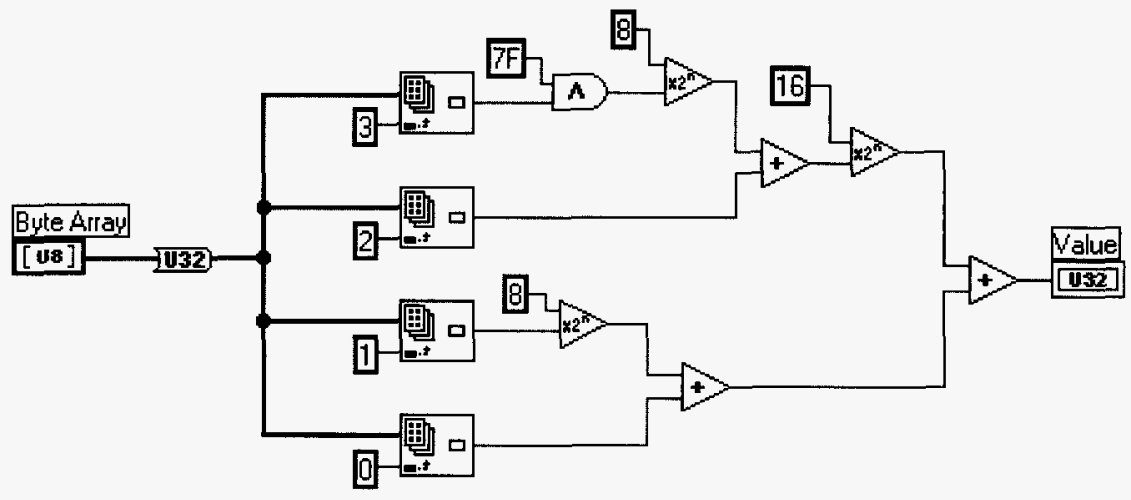



Position in Hierarchy

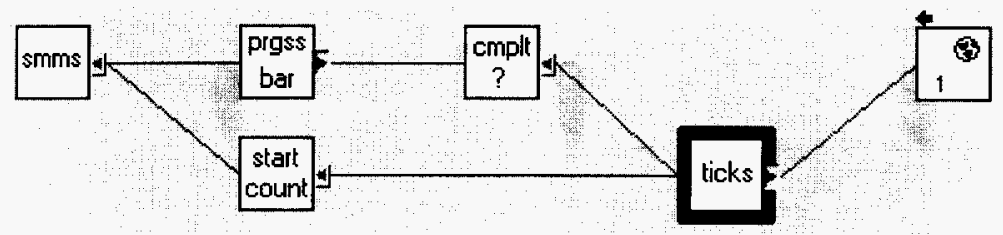

Connector Pane

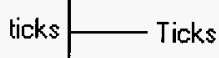

\section{Get Number of Ticks.vi}

This VI returns the number of MCA ticks or clock cycles that is equal to the specified global variable "Sample Time". The MCA clock cycle rate is equal to 50 times per second. The "Sample Time" value is in units of minutes.

\section{Block Diagram}

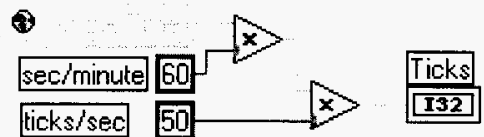




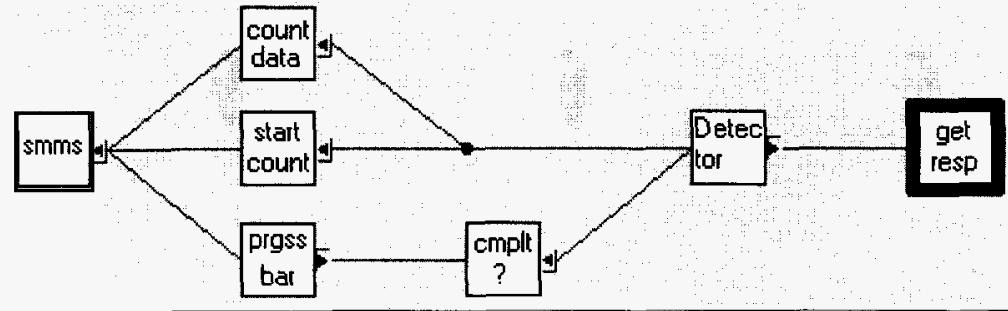

Connector Pane

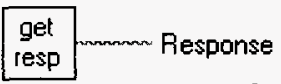

\section{Get Response.vi}

This VI processes MCA (Multichannel Analyzer) to PC messages. (refer to MCA user manual for protocol format)

This VI assumes that the page select port (address 292 hex) is set to a binary 8 mapping MCB 1 mailbox to the shared memory page.

This VI accomplishes this task by accessing the following dual-port memory locations:
Address
Name
Description
D000:03E0
MCB\$INFLG
Set to FF hex by the MCB to indicate that a message from the
MCB to the PC is ready. Set to 0 by the PC when the message is accepted.
D000:03FC MCB\$INLN Least significant byte of the 16- bit integer that is the length of message in MCB\$INBUF.
D000:03FE MCB\$INLEN+2 Most significant byte of the 16- bit integer that is the length of message in MCB\$INBUF.
D000:0400 MCB\$INBUF First of 512 bytes that hold messages sent from theMCB to the PC. The number of bytes in the message is stored in MCB\$INLEN. 
Rev. 0

Page 60 of 80

\section{Check for message}
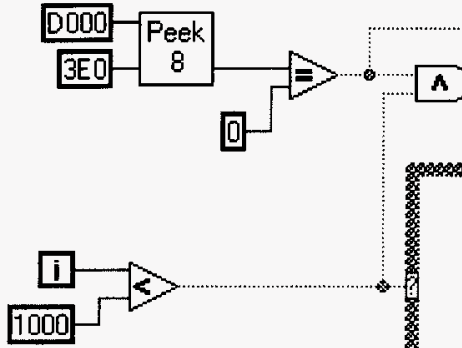

A $). .$.

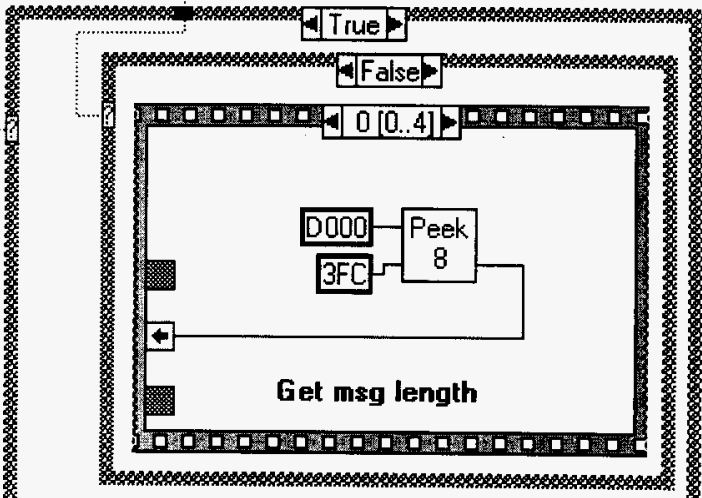

X

First, this VI checks the dual-port memory location MCB\$INFLG for a value other than zero indicating a message from the MCA is ready for the PC. If, after checking 1,000 times a message is not received, an error message "MCA not responding" is generated. Upon detecting a pending message (a false condition is the second level case statement), five sequence frames are executed.

Frame 0, reads dual-port memory location MCB\$INLEN LSB. 
Rev. 0

Page 61 of 80

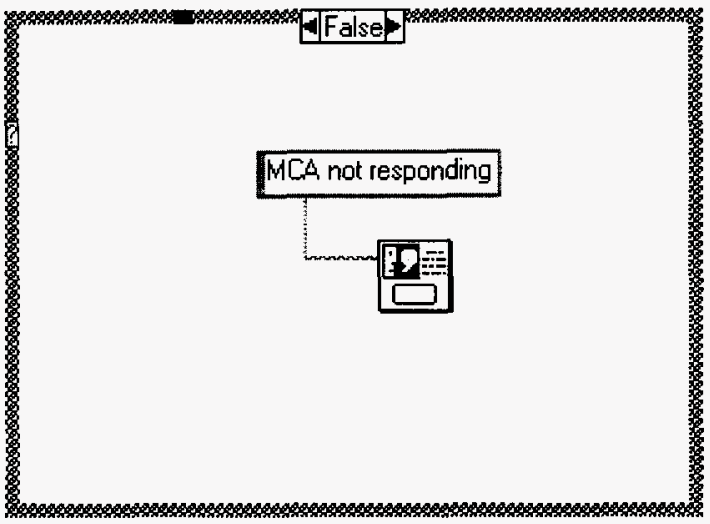

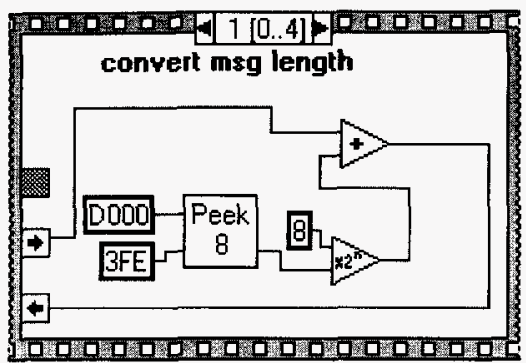

Frame 1, reads dual-port memory location MCB\$INLEN+2 MSB. Next, it multiplies this value by 256 and then adds the LSB from frame 0 . The resultant value is equal to the number of bytes in the received message.

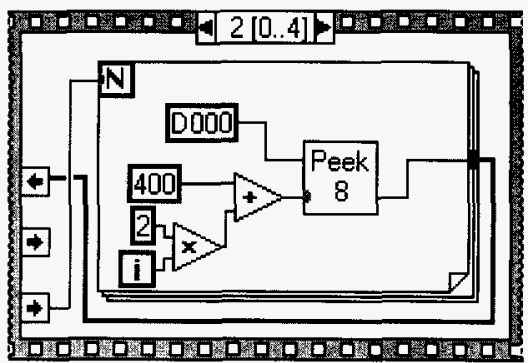

Frame 2, reads the number of bytes calculated in Frame 1 from dual-port memory location MCB\$INBUF. Note, the mailbox bytes appear every second byte in the mailbox page. 


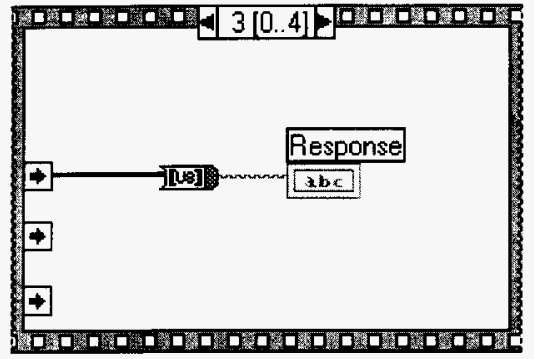

Frame 3, converts Frame 2's data to an ASCII string which is returned to the calling VI as the "Response" variable.

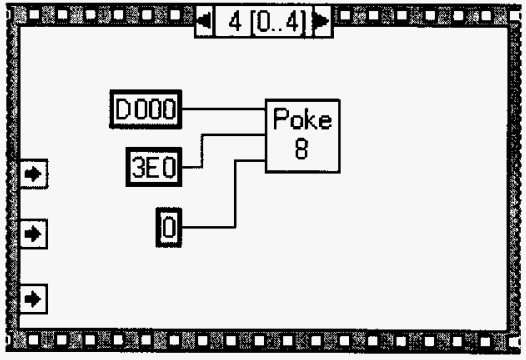

Frame 4, tells the MCA that the message has been processed by writing a zero to dualport memory location MCB\$INFLG.

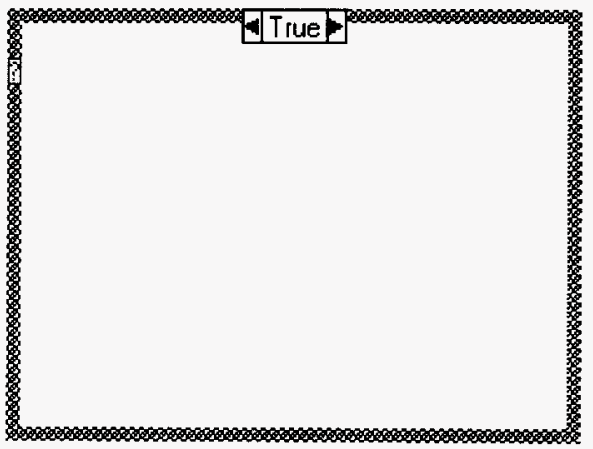


WHC-SD-WM-CSDD-017

Rev. 0

Page 63 of 80

3.5.7.5. Get Spectrum.vi

Position in Hierarchy

data

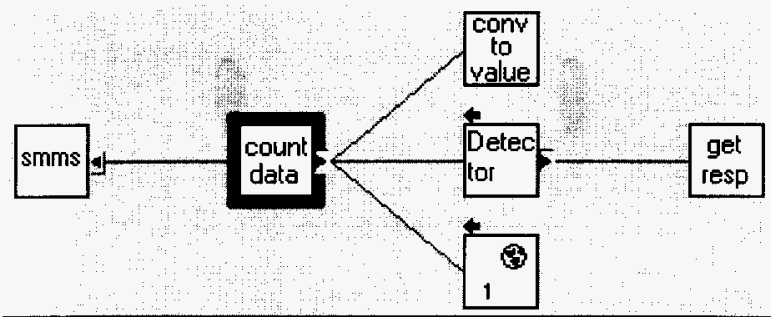

Connector Pane

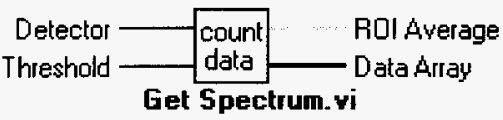

This VI reads 1,024 data points from the MCA and stores the data into an array. It also calculates the overall counts per minute. (refer to the MCA user manual for protocol format)

Block Diagram

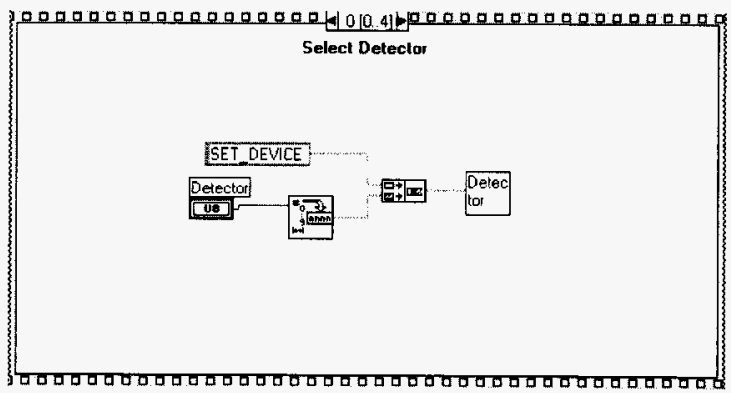

Frame 0, creates a string made up of "SET_DEVICE" followed by the converted detector value and sends this string to "Send Command.vi". 


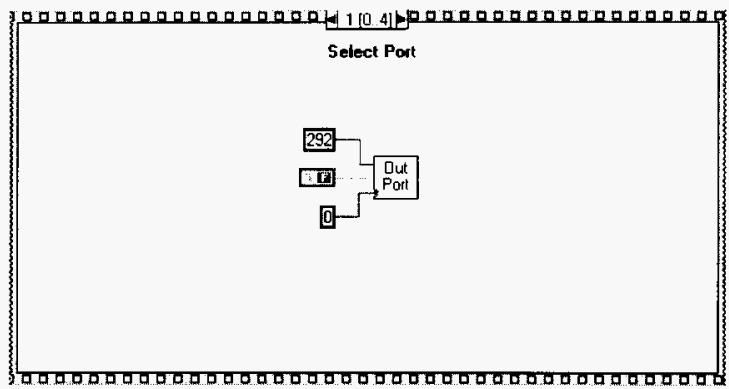

Frame 1, sets the page select I/O port (address 292 hex) to 0, which maps MCB 1 data memory to the shared memory page.

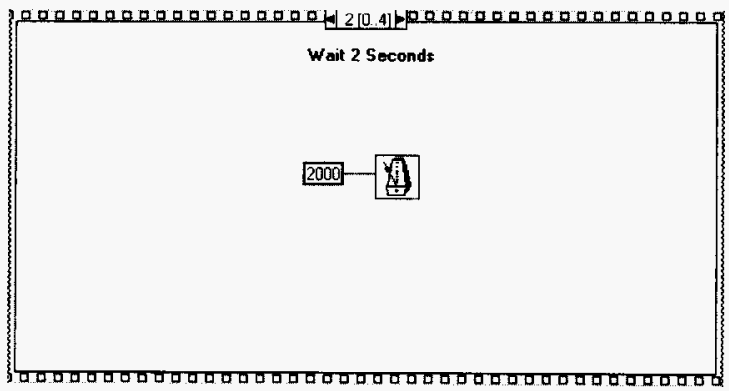

Frame 2, executes a two second delay.

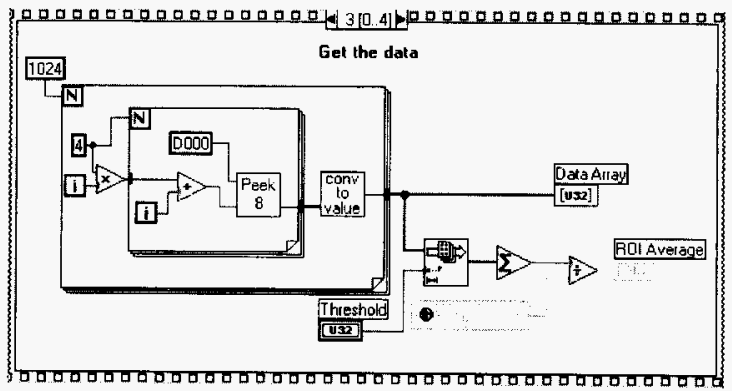

Frame 3, reads 4,096 bytes from the dual-port memory location D000:0000 in four byte blocks. Each block is then converted into one 32 bit value, generating a 1,024 32 bit array which is returned to the calling VI as variable "Data Array". Then a subset of the array, starting at an index value equal to the "threshold" variable, are summed. The summed value is then divided 
by the global variable "Sample Time". This final value is then returned as the "ROI Average" variable to the calling VI.

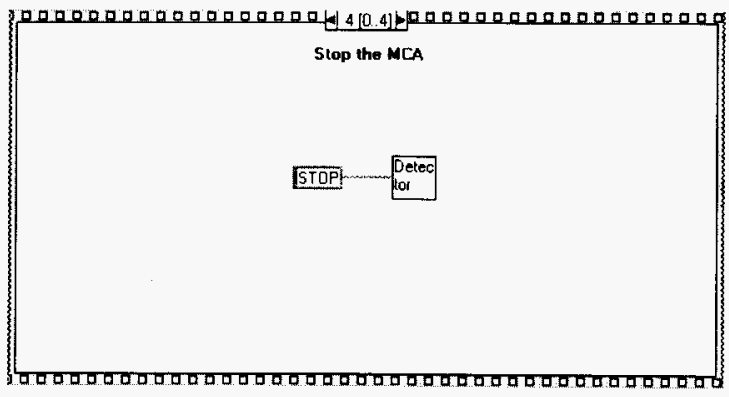

Frame 4, creates a string made up of "STOP" and then sends this string to "Send Command.vi". 
WHC-SD-WM-CSDD-017

Rev. 0

Page 66 of 80

3.5.7.6. Progress Bar.vi

Position in Hierarchy

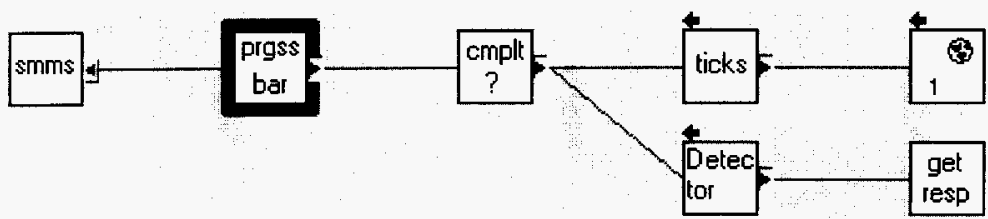

Front Panel
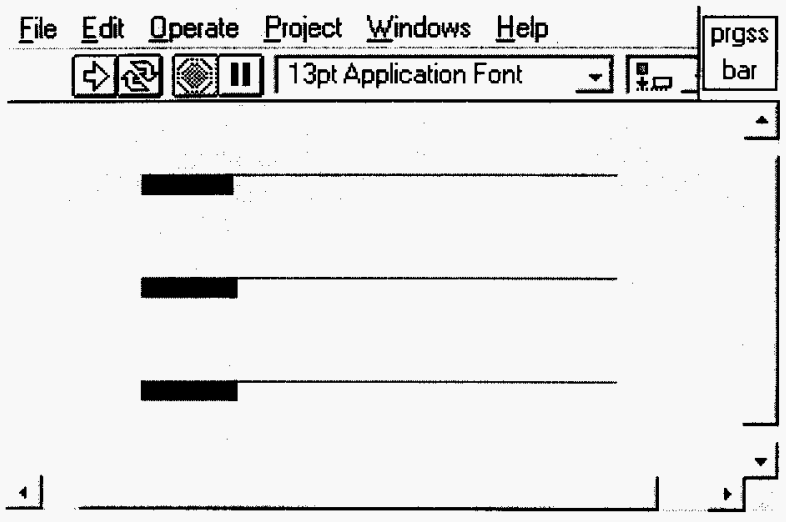

Connector Pane

$$
\begin{aligned}
& \text { prgss } \\
& \text { bar }
\end{aligned}
$$

\section{Progress Bar.vi}

This VI continually updates three progress bars, that correlate to the percent of completion of the MCA's data collection for the three detectors, until all three bars reach 100 percent. This is accomplished by executing a "while" structure which continuously monitors the status output of the following 3 sequence frames. Upon detecting a "false" state on all three sequence frames' statuses, this VI terminates. 


\section{Block Diagram}

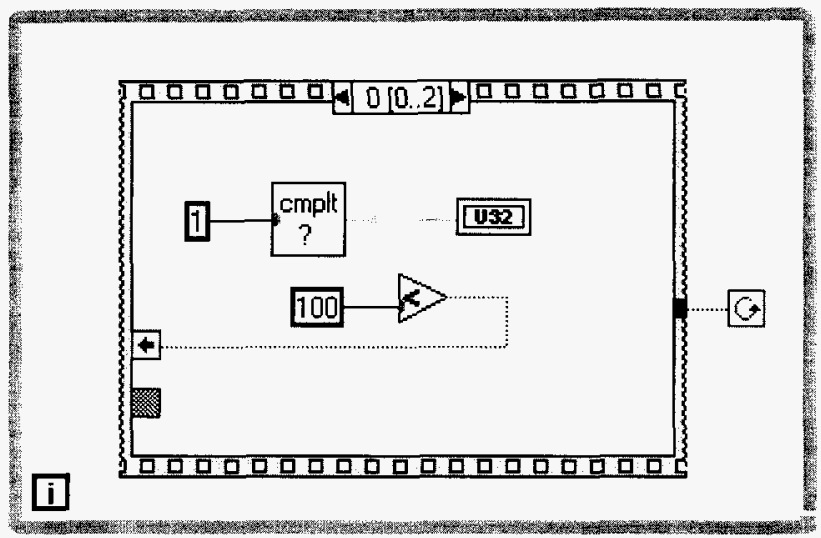

Frame 0, specifies detector \#1 and executes "Check Progress.vi" which returns the percent of completion value for the detector. The value returned updates the panel bar display for the detector. Then the value returned is compared to 100 , and if the value is less than 100 , a "true" status is generated.

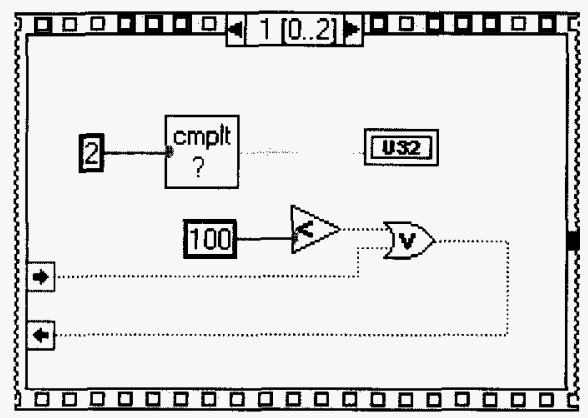

Frame 1, specifies detector \#2, and executes "Check Progress.vi" which returns the percent of completion value for the detector. The value returned updates the panel bar display for the detector. Then the value returned is compared to 100 , and if the value is less than 100 , a "true" status is generated. which is "ORed" with the status generated from Frame 0 . If, either states are "True", then this frame generates a "true" status.

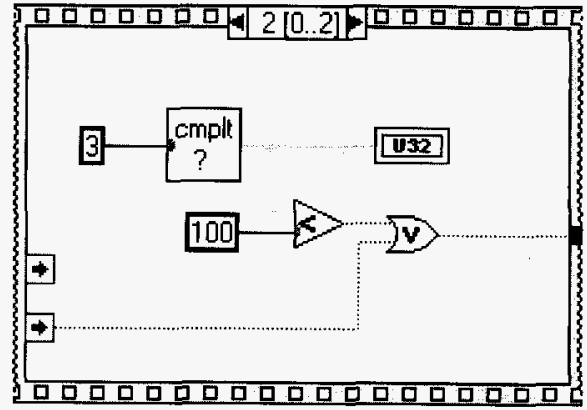

Frame 2, specifies detector \#3, and executes "Check Progress.vi" which returns the percent of completion value for the detector. The value returned updates the panel bar display for the detector. Then the value returned is compared to 100 , and if the value is less than 100 , a "true" status is generated. which is "ORed" with the status generated from Frame 0. If, either states are "True", then this frame generates a "true" status. 
Position in Hierarchy

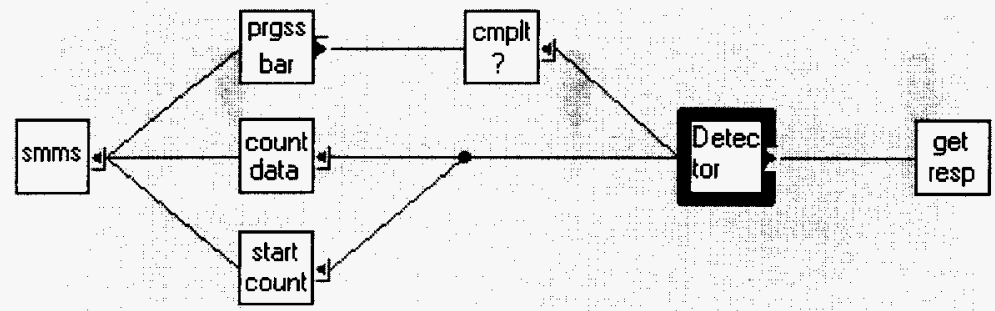

Connector Pane

Command anmonn Detec

\section{Send Command. vi}

This VI sends a command to the MCA in the NIMBIN and returns the response. (refer to MCA user manual for protocol format)

This VI accomplishes this task by accessing the following dual-port memory MCA mailbox locations:

$\frac{\text { Address }}{\text { D000:0000 }} \quad \frac{\text { Name }}{\text { MCB\$OUTFLG }}$

D000:0002 MCB\$TEST

D000:001C MCBSOUTLEN

D000:001E

D000:0020

D000:03E0
MCB\$INFLG
MCB\$OUTBUF
Description

Set to FF hex by the PC to indicate that a message from the $P C$ to the $M C B$ is ready. Set to 0 by the MCB when the message is accepted.

Ignored by all MCBs. May be read and written by PC. Used by PC to determine if MCB shared memory exists.

Least significant byte of the 16-bit integer that is the length of the message in MCB\$OUTBUF.

MCB\$OUTLEN+2 Most significant byte of the 16-bit integer that is the length of the message in MCB\$OUTBUF.

First of 480 bytes that hold messages sent from thePC to the $\mathrm{MCB}$. The number of bytes in the message is stored in MCB\$OUTLEN.

Set to FF hex by the MCB to indicate that a message from the $M C B$ to the $P C$ is ready. Set to 0 by the PC when the message is accepted. 
D000:03FC MCB\$INLEN Least significant byte of the 16-bit integer that is the length of the message in MCB\$INBUF.

D000:03FE MCB\$INLEN+2 Most significant byte of the 16-bit integer that is the length of the message in MCB\$INBUF.

D000:0400 MCB\$INBUF First of 512 bytes that hold messages sent from the MCB to the PC. The number of bytes in the message is stored in MCB\$INLEN.

\section{Block Diagram}

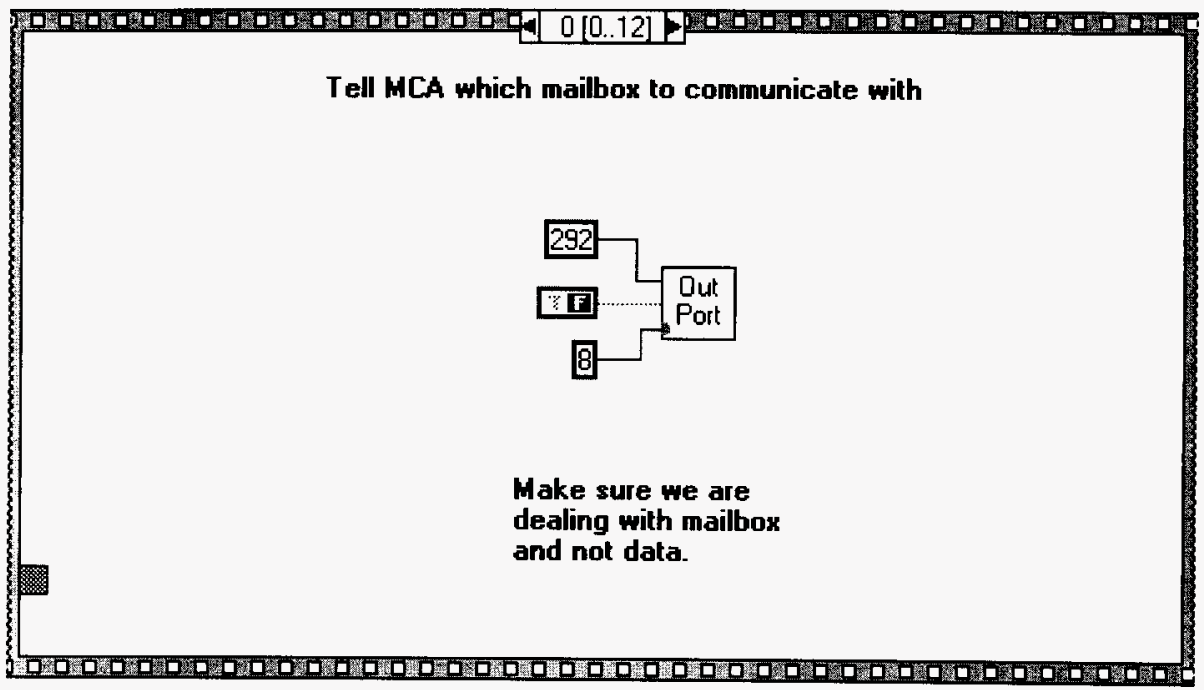

Frame 0, writes a binary 8 to page select port (address 292 hex) to map the MCB 1 mailbox to the shared memory page. 


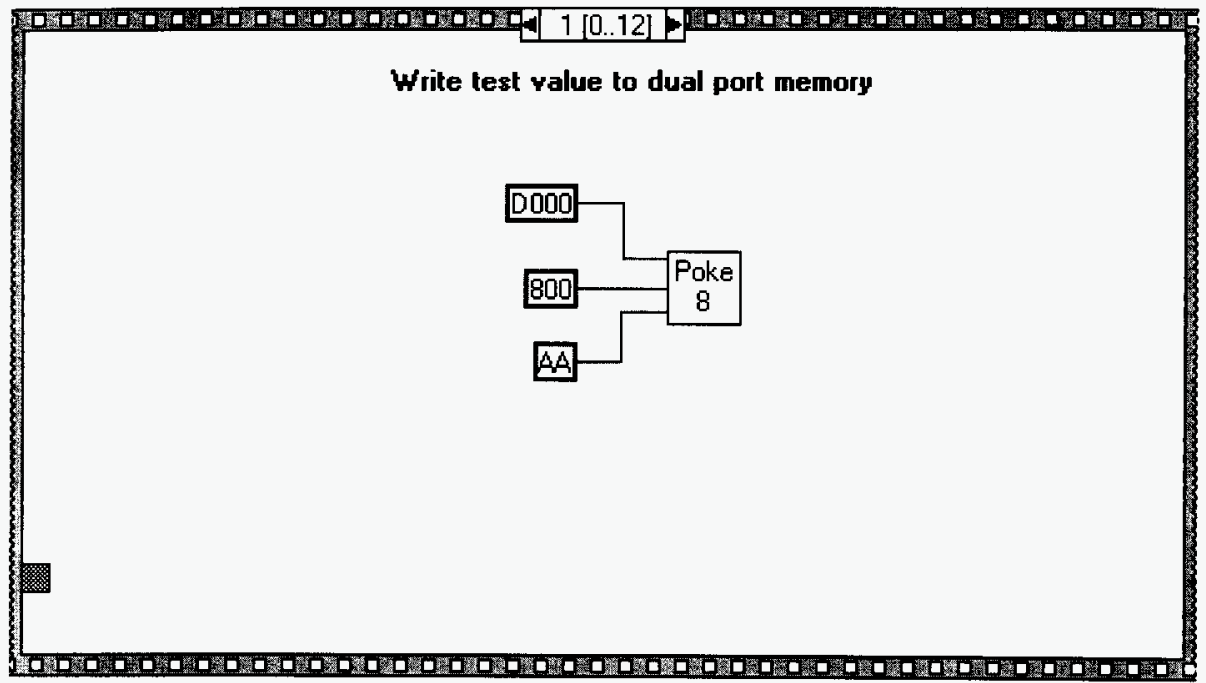

Frame 1, writes a test value AA hex to dual-port memory location MCB\$TEST.

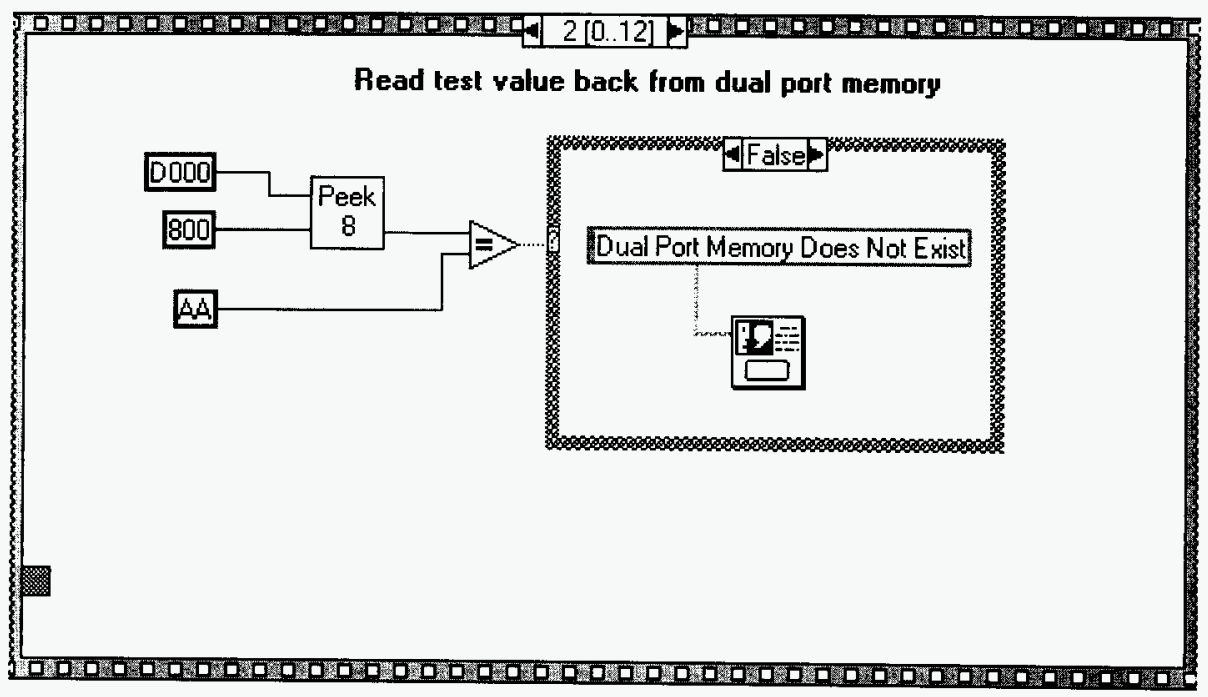

Frame 2, reads dual-port memory location MCB\$TEST and compares the read value to AA hex. If not equal, an error message "Dual Port Memory Does Not Exist" is generated. 


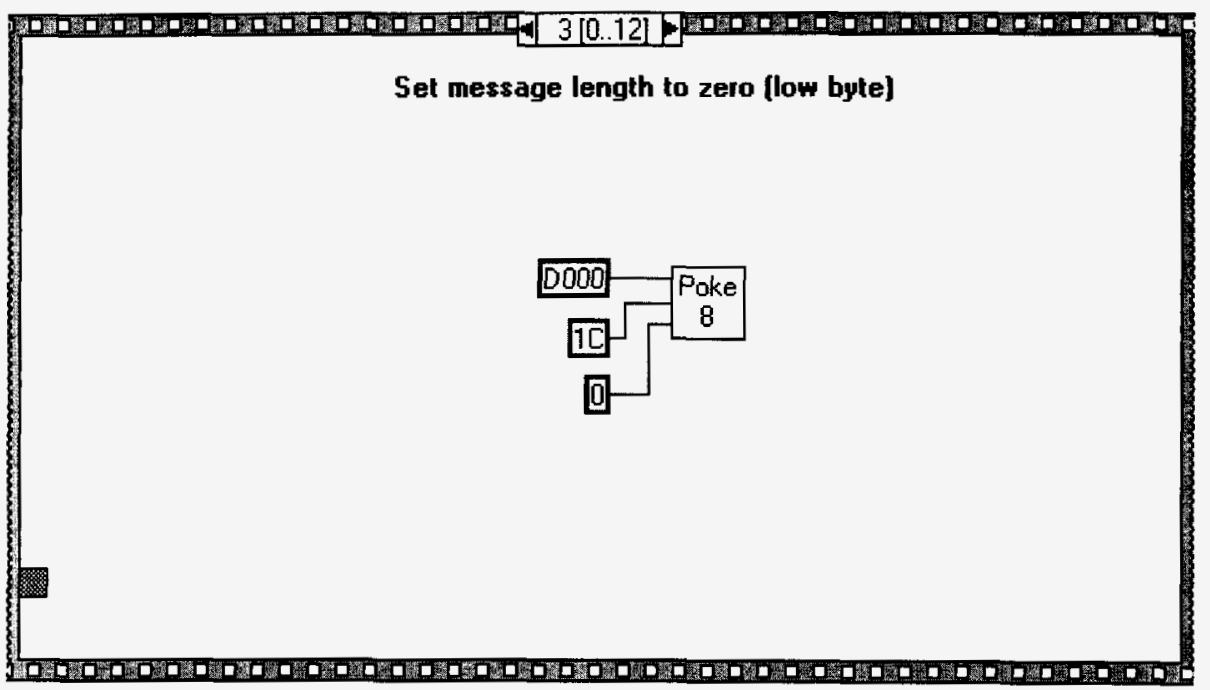

Frame 3, writes 0 to dual-port memory location MCB\$OUTLEN LB.

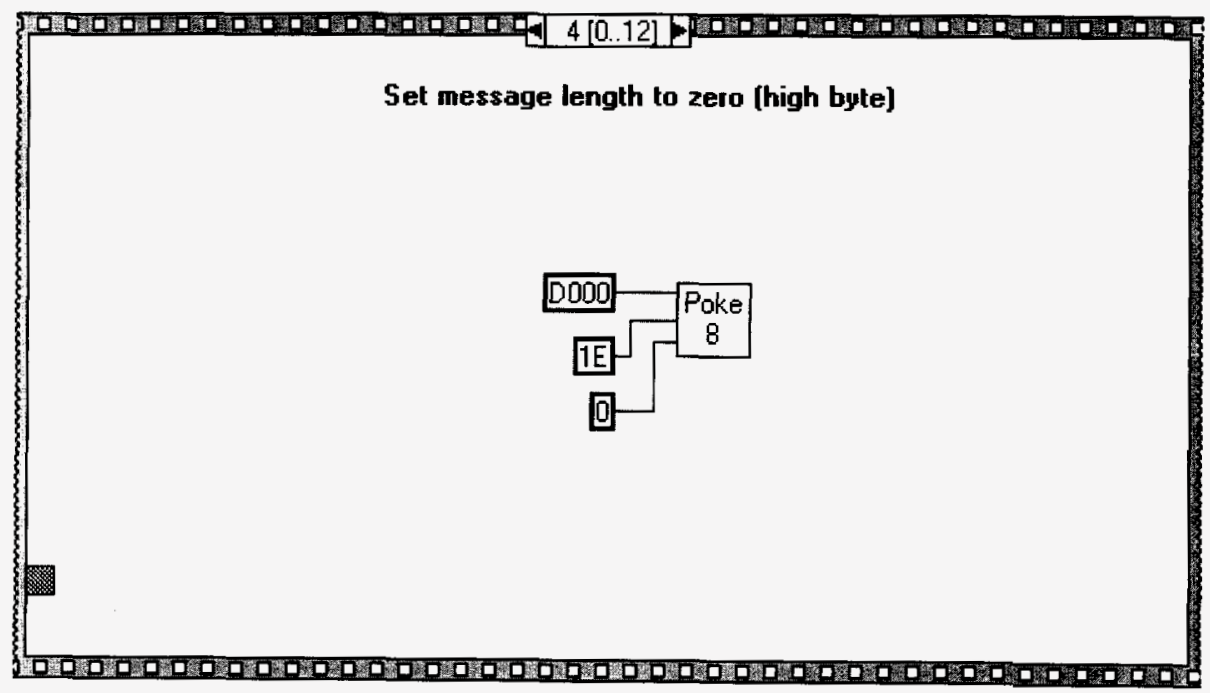

Frame 4, writes 0 to dual-port memory location MCB\$OUTLEN+2 MCB. 


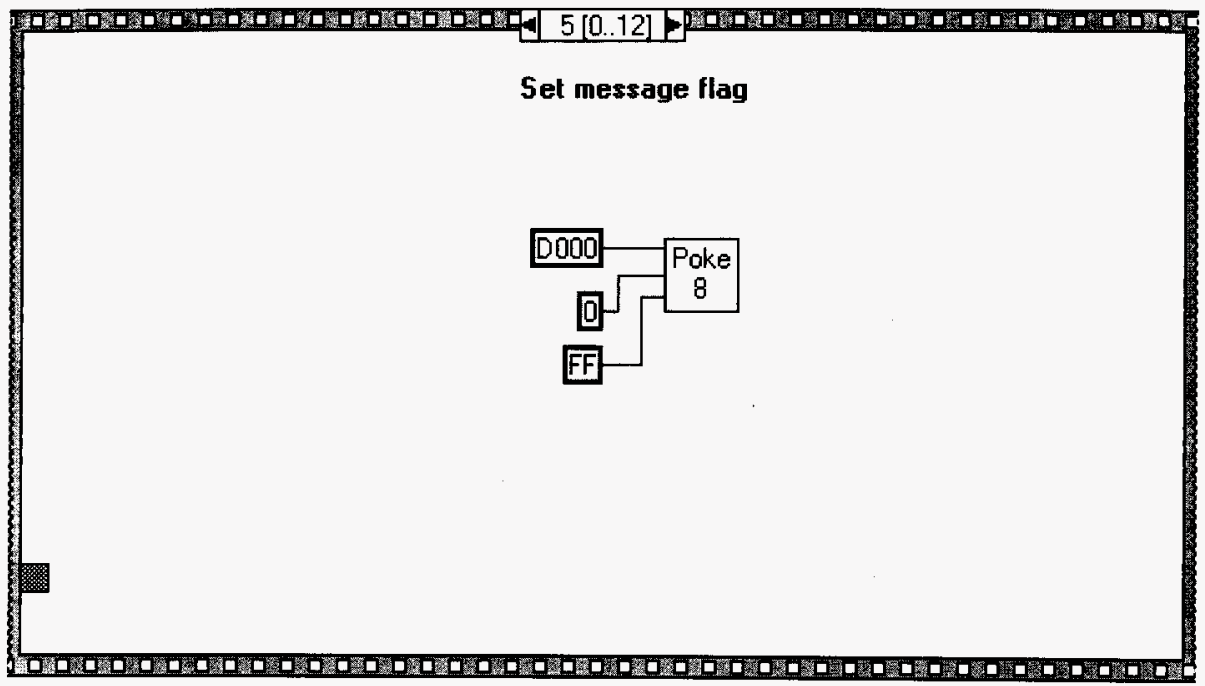

Frame 5, writes FF hex to dual-port memory location MCB\$OUTFLG.

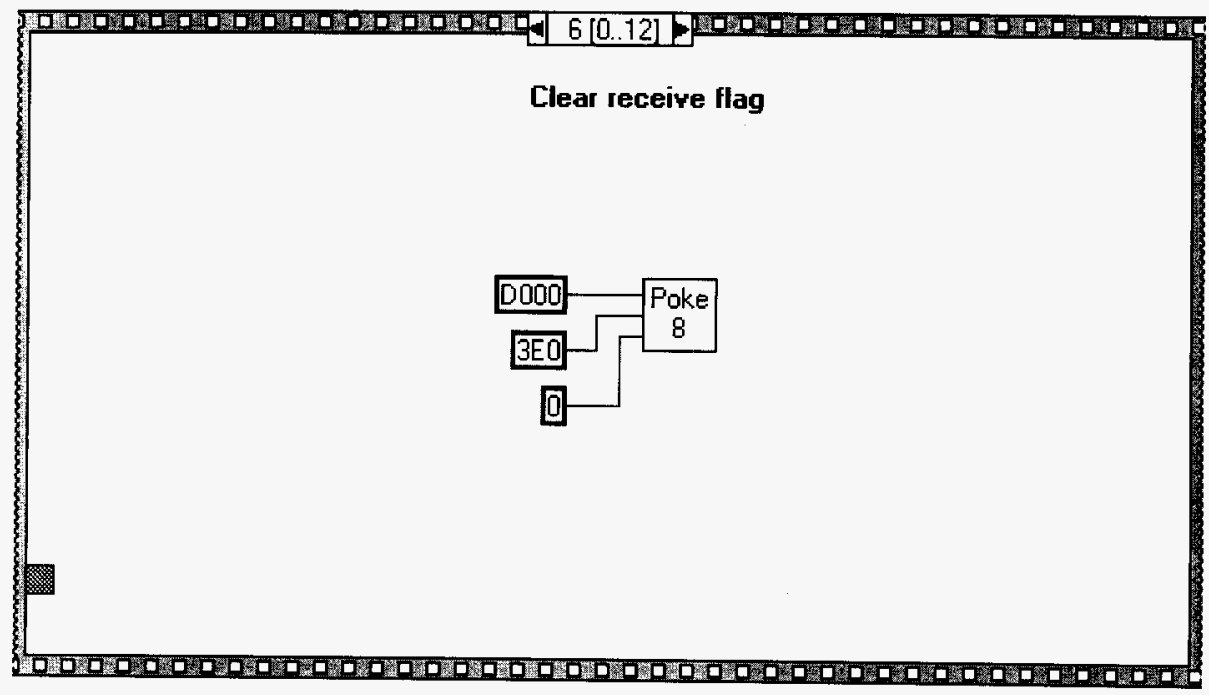

Frame 6, writes 0 to dual-port memory location MCB\$INFLG. 


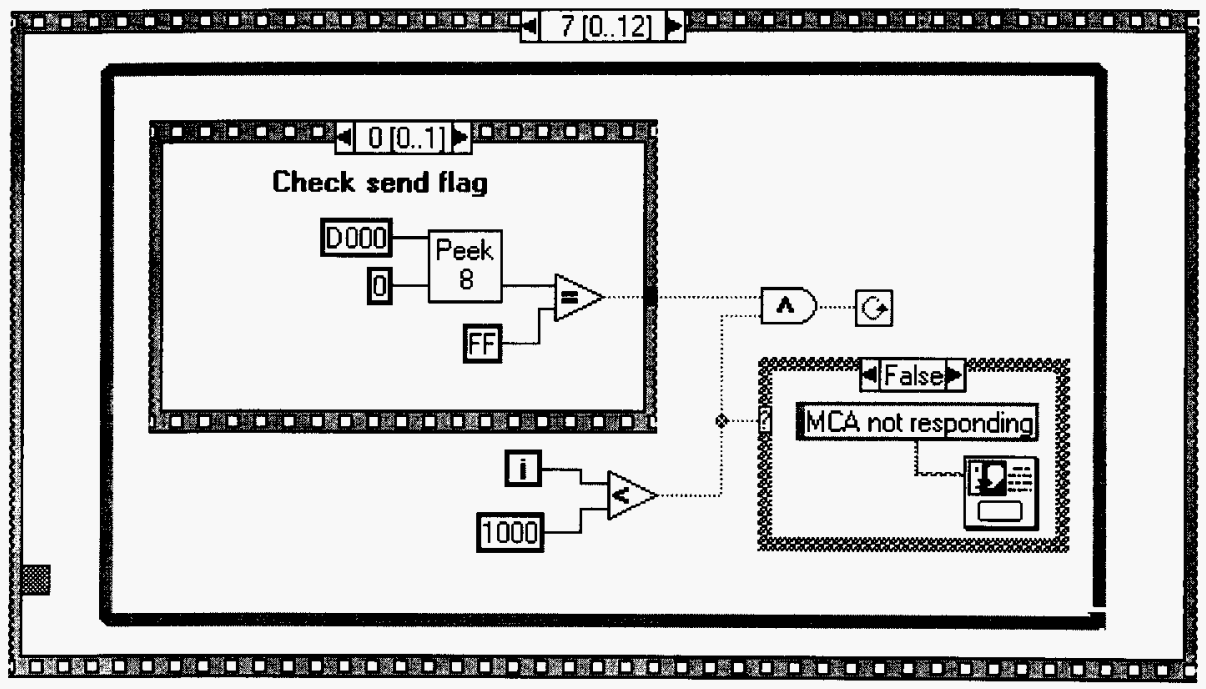

Frame 7, checks the dual-port memory location MCB\$OUTFLG for a value other than FF hex, indicating the MCA has accepted the message. If, after checking 1,000 times, the message has not been accepted, an error message "MCA not responding" is generated. Upon detecting the MCA accepting the message, the next sequence frame is executed.

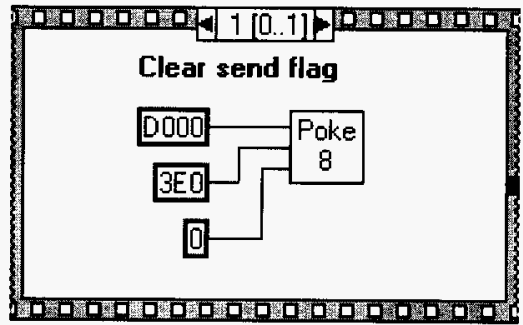




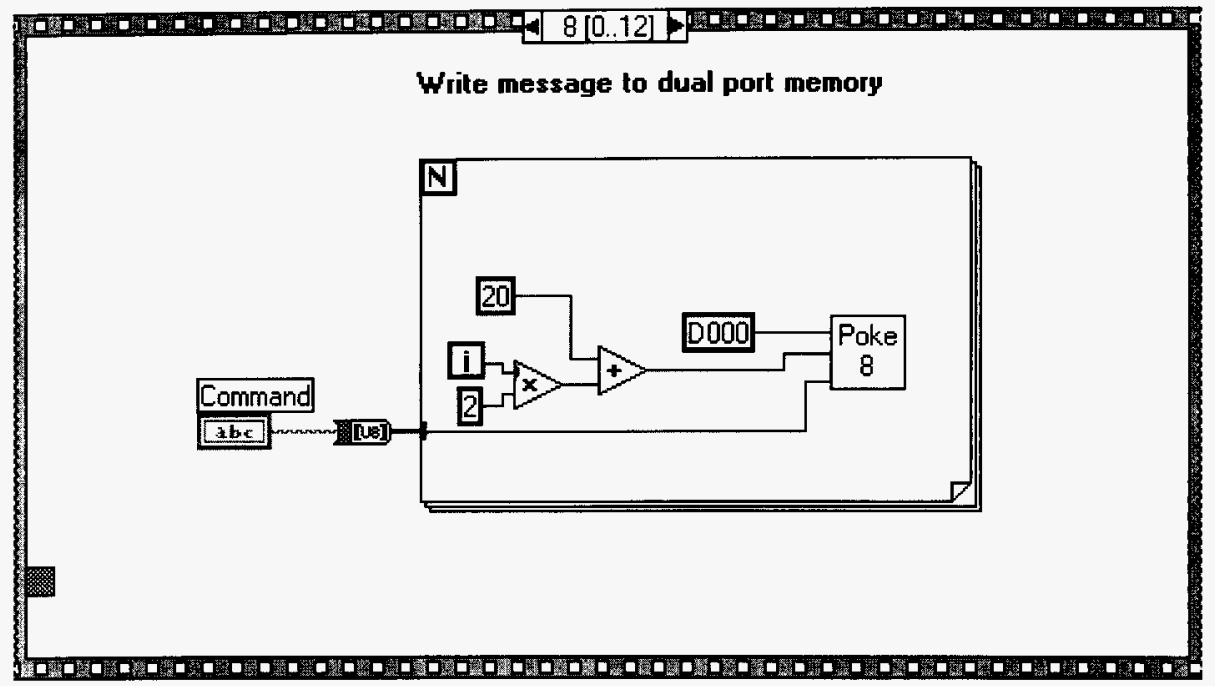

Frame 8, writes the calling VI's "Command" string variable to the dual-port memory location MCB\$OUTBUF. Note, the mailbox bytes appear every second byte in the mailbox page.

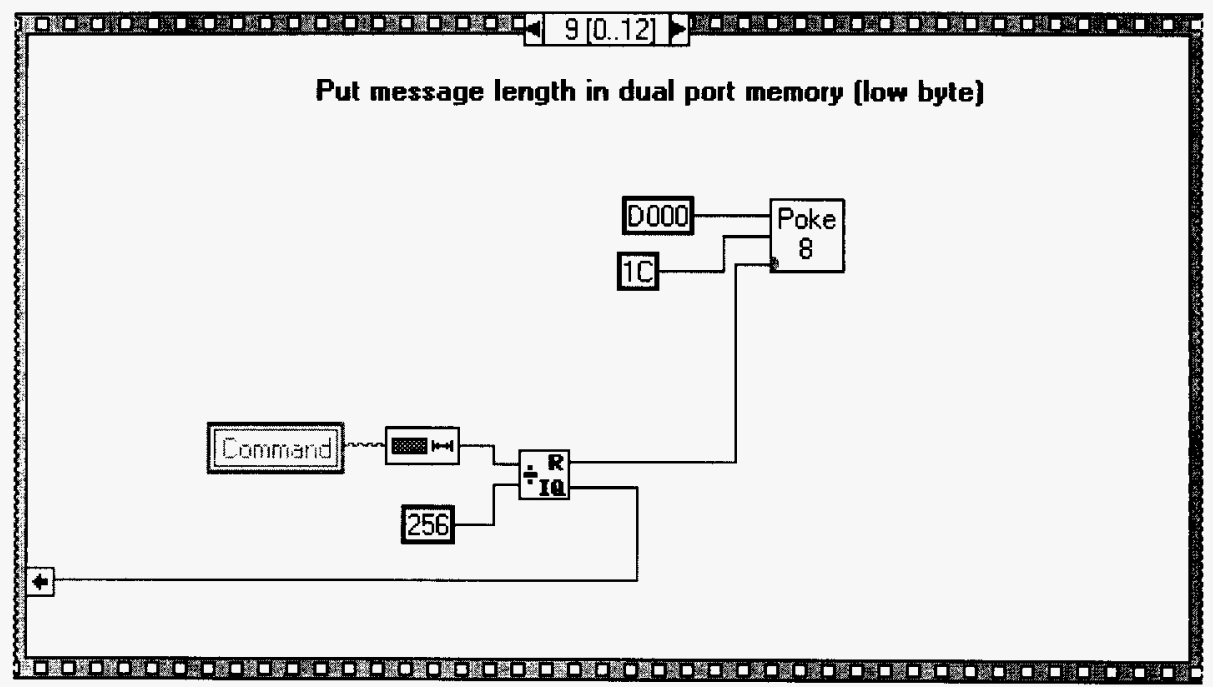

Frame 9, writes the command length LSB to the dual-port memory location MCB\$OUTLEN LSB. 


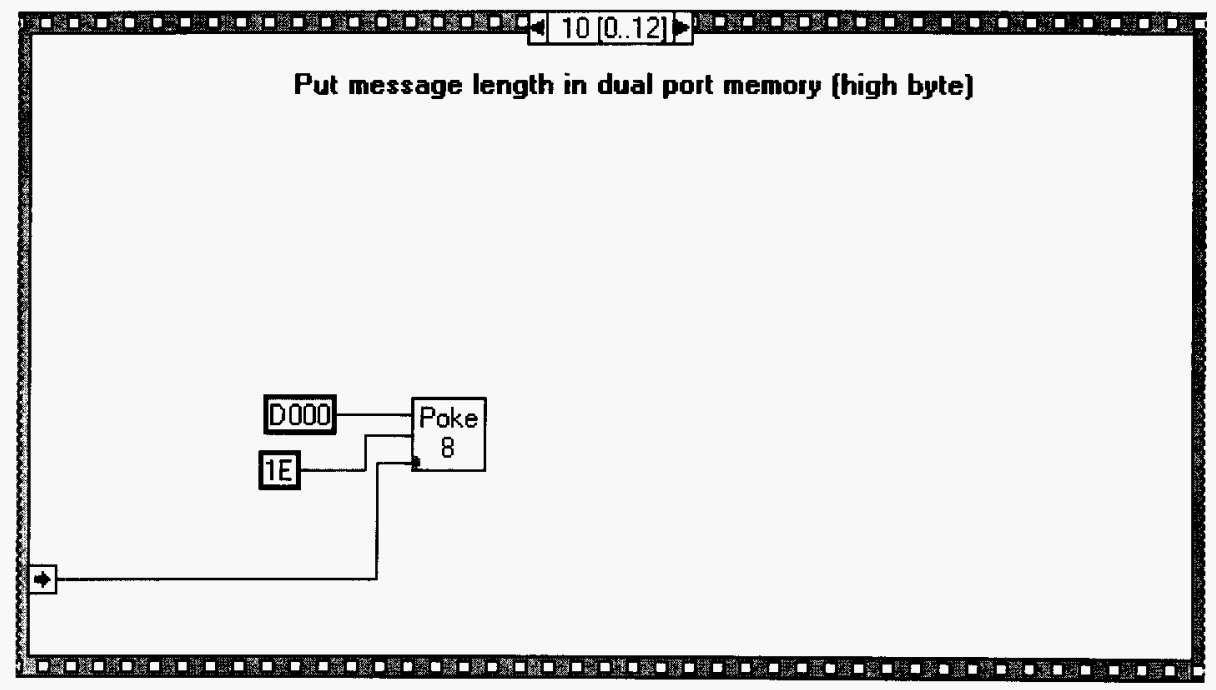

Frame 10, writes the command length MSB to the dual-port memory location MSB \$OUTLEN+2.

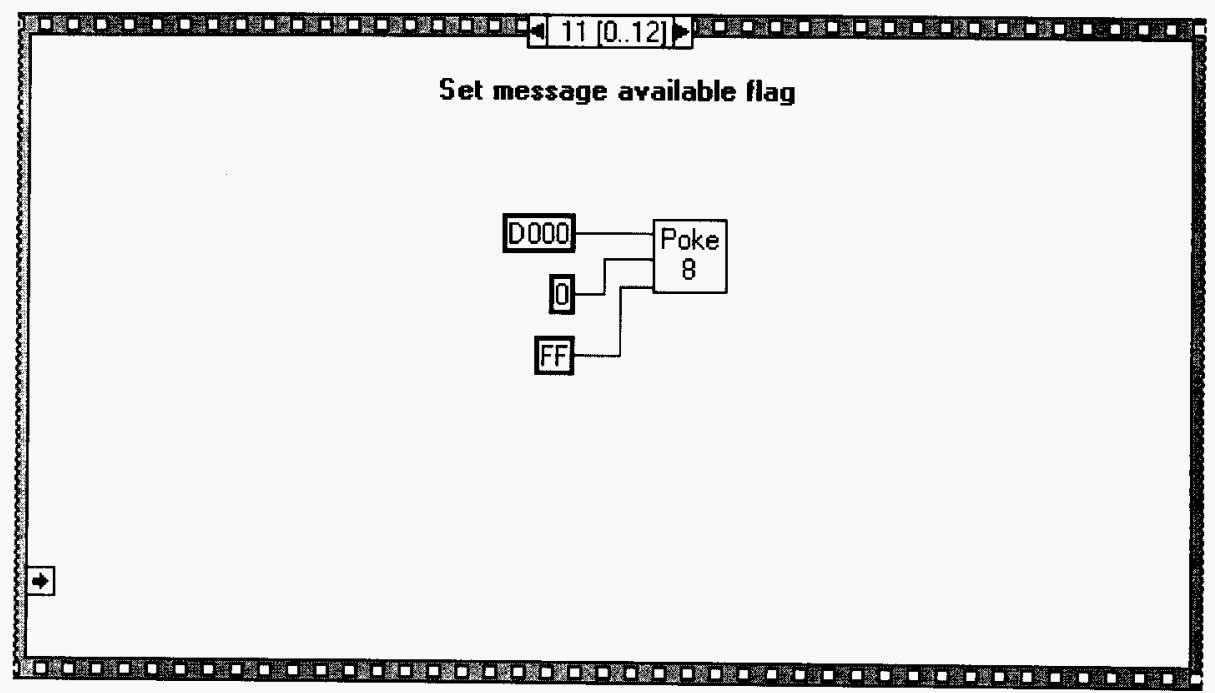


WHC-SD-WM-CSDD-017

Rev. 0

Page 76 of 80

Frame 11, writes FF hex to the dual-port memory location MCB\$OUTFLG indicating that a message from the $\mathrm{PC}$ to the MCB is ready.

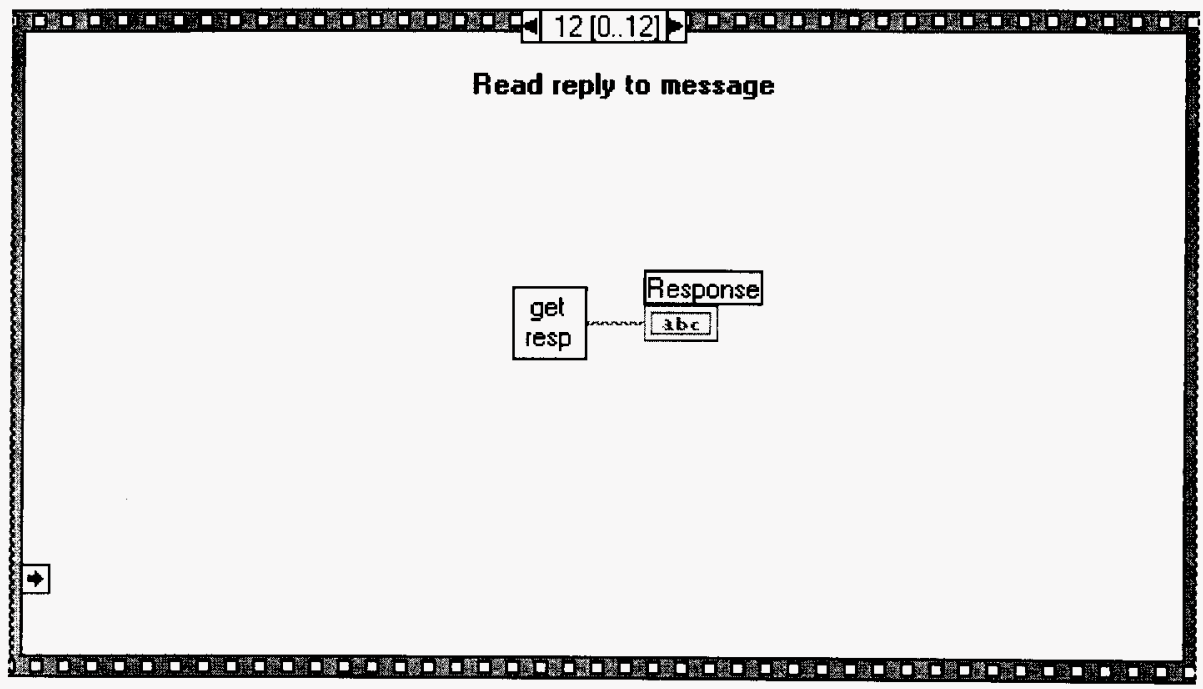

Frame 12, retrieve response by calling "Get Response.vi". 
Position in Hierarchy

count

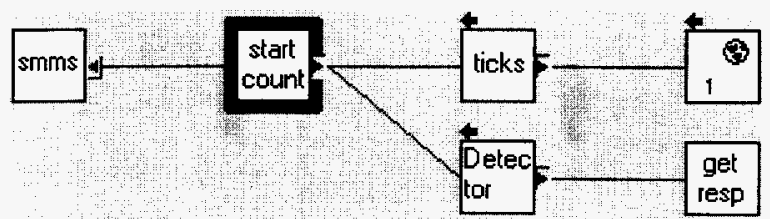

Connector Pane

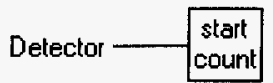

\section{Start Counting. vi}

Initiates the MCA counting for the specified detector (refer to the MCA user manual).

Block Diagram

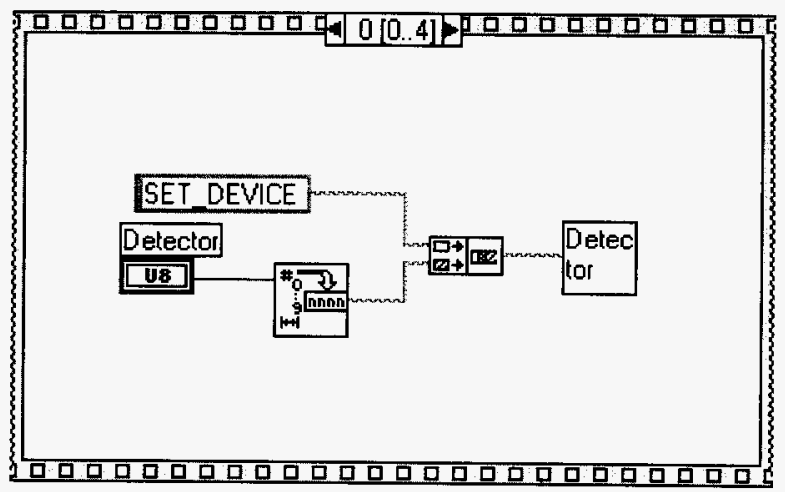

Sequence Frame 0, creates a string "SET_DEVICE" followed by the converted detector value and sends this string to "Send Command.vi". 


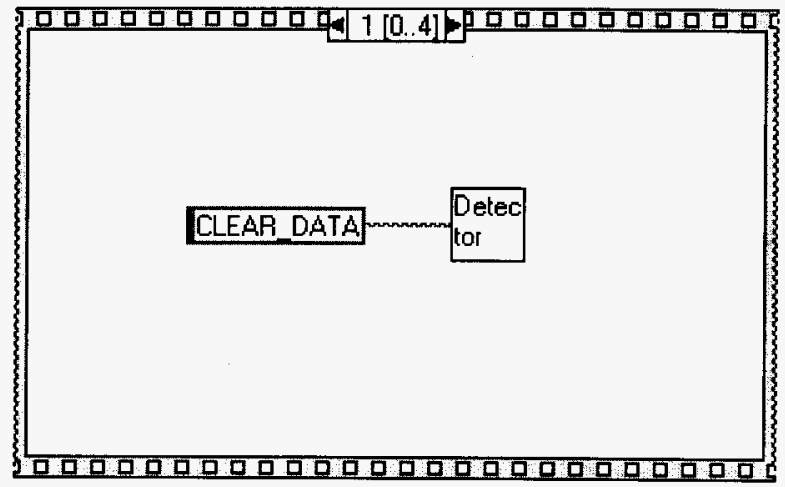

Sequence Frame 1, creates a string "CLEAR_DATA" and sends this string to "Send Command.vi".

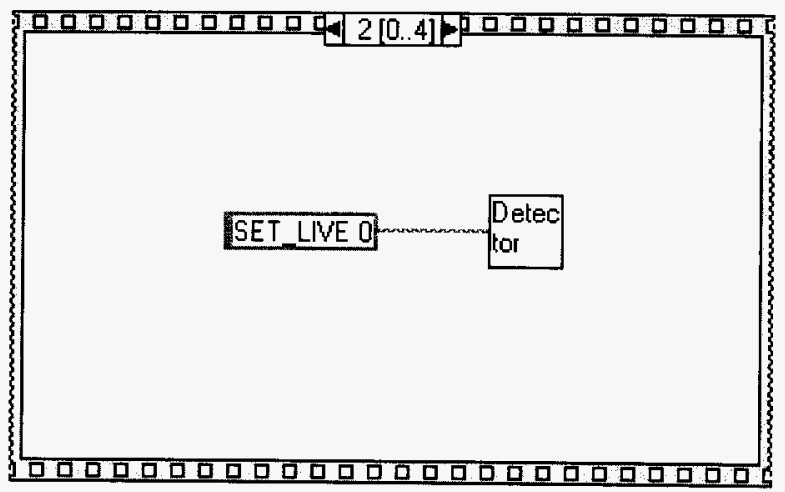

Sequence Frame 2, creates a string "SHOW_LIVE 0 " and sends this string to "Send Command.vi". 
Rev. 0

Page 79 of 80

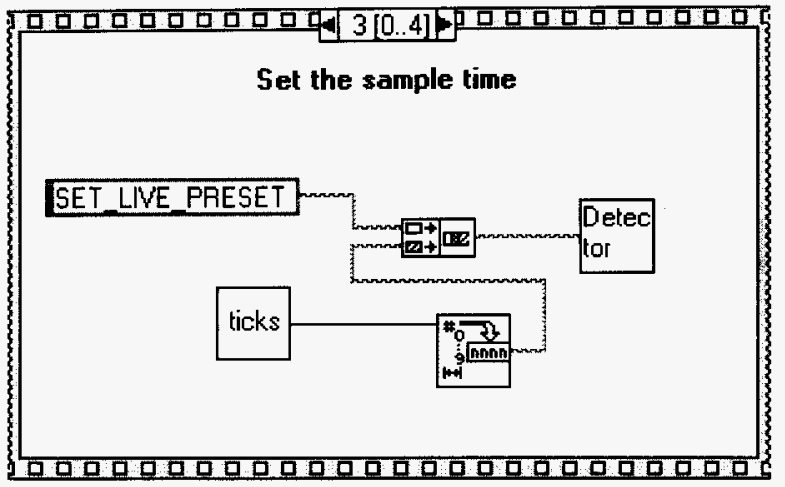

Sequence Frame 3, creates a string "SET_LIVE_PRESET" followed by the converted value returned from "Get Number of Ticks.vi" and sends this string to "Send Command.vi".

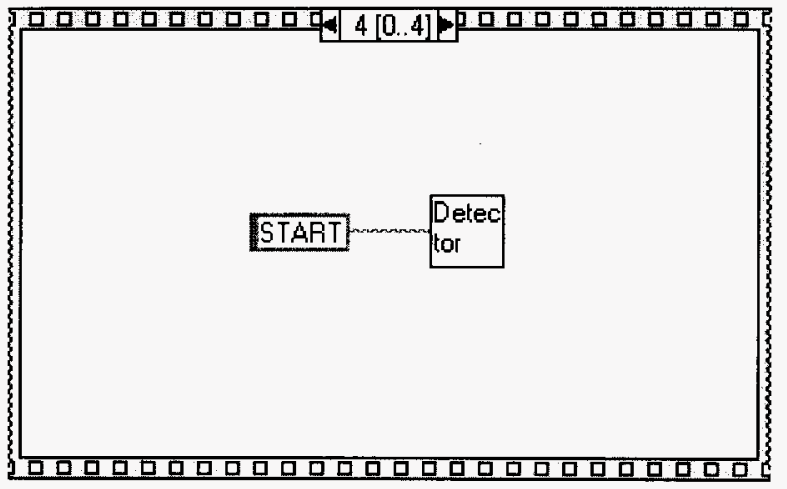

Sequence Frame 4, creates a string "START" and sends this string to "Send Command.vi". 


\section{REFERENCES}

1. WHC-CM-6-1, "Standard Engineering Practices".

2. ANSI/IEEE Standard 829-1983, "IEEE Standard for Software Test Documentation".

3. Gimera, M., 1996, Software Requirements Specification for Surface Moisture Monitor, WHC-SD-WM-SFR-010, Rev. 0, Westinghouse Hanford Company, Richland, Washington.

4. TCM2 Electronic Compass Module User's Manual, Rev. 1.02, Precision Navigation Inc, Mountain View, California.

5. ADCAM/IBM Interface Card Manual, Rev. 03, EG\&G Ortec, Oak Ridge, Tennessee.

6. SPA 2 Serial Parallel Translator Manual, Max Stegmann $\mathrm{GmbH}$, Donaueschingen, Germany.

7. LabVIEW User Manual, National Instruments, Austin, Texas.

8. LabVIEW Function Reference Mamual, National Instruments, Austin, Texas. 


\section{DISTRIBUTION SHEET}

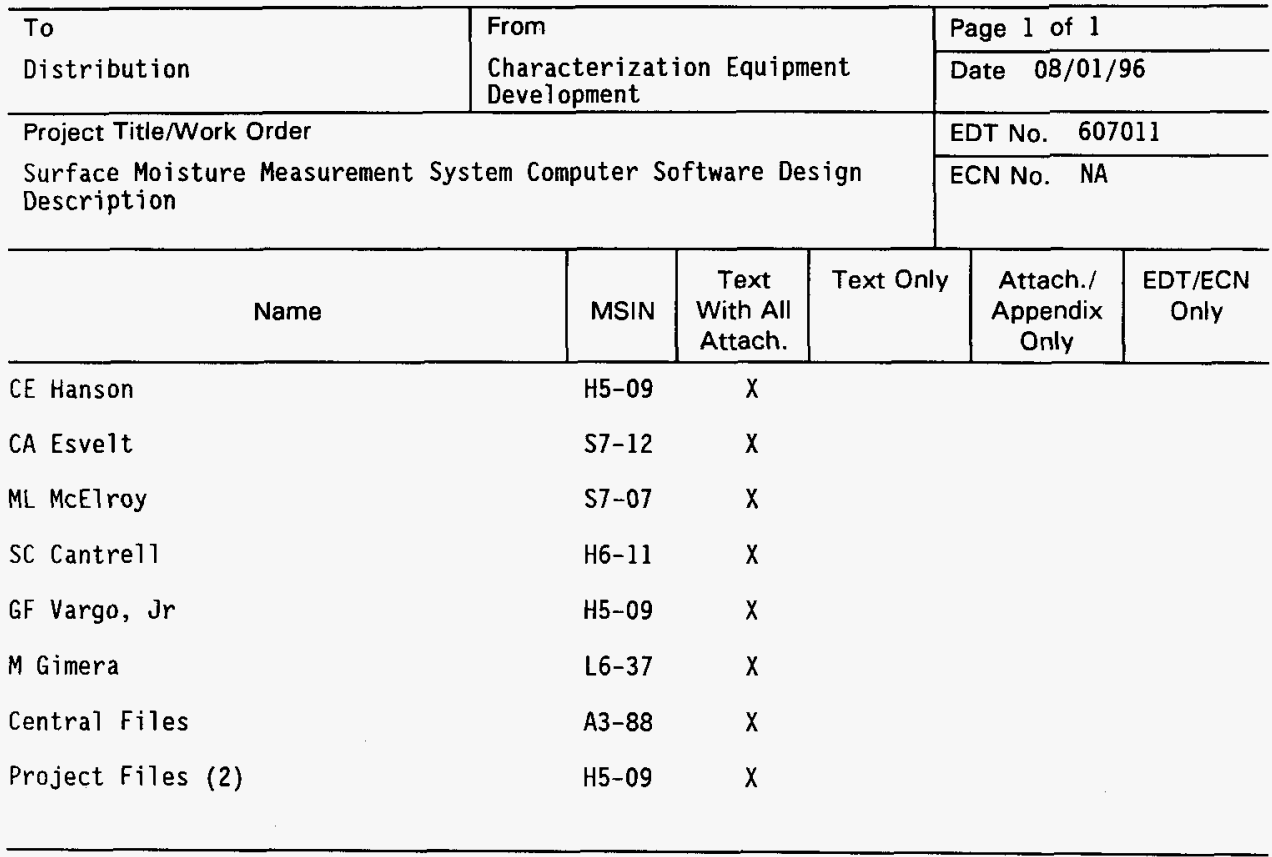

